\title{
Review
}

\section{Different Cognitive Frailty Models and Health- and Cognitive-related Outcomes in Older Age: From Epidemiology to Prevention}

\author{
Francesco Panza a,b,c,1,* Madia Lozupone ${ }^{\mathrm{b}, 1, *}$, Vincenzo Solfrizzi ${ }^{\mathrm{d}}$, Rodolfo Sardone ${ }^{\mathrm{e}}$, \\ Vittorio Dibello ${ }^{\mathrm{f}}$, Luca Di Lena ${ }^{\mathrm{e}}$, Francesca D’Urso ${ }^{\mathrm{g}}$, Roberta Stallone ${ }^{\mathrm{b}}$, Massimo Petruzzi ${ }^{\mathrm{f}}$, \\ Gianluigi Giannelli $^{\mathrm{e}}$, Nicola Quaranta ${ }^{\mathrm{h}}$, Antonello Bellomo ${ }^{\mathrm{g}}$, Antonio Greco ${ }^{\mathrm{a}}$, Antonio Daniele ${ }^{\mathrm{i}}$, \\ Davide Seripa $^{\mathrm{a}}$ and Giancarlo Logroscino ${ }^{\mathrm{b}, \mathrm{c}}$ \\ ${ }^{a}$ Department of Medical Sciences, Geriatric Unit and Laboratory of Gerontology and Geriatrics, \\ IRCCS “Casa Sollievo della Sofferenza”, San Giovanni Rotondo, Foggia, Italy \\ ${ }^{\mathrm{b}}$ Department of Basic Medicine, Neurodegenerative Disease Unit, Neuroscience, and Sense Organs, \\ University of Bari Aldo Moro, Bari, Italy \\ ${ }^{\mathrm{c}}$ Department of Clinical Research in Neurology, University of Bari Aldo Moro, "Pia Fondazione Cardinale \\ G. Panico", Tricase, Lecce, Italy \\ ${ }^{\mathrm{d}}$ Geriatric Medicine-Memory Unit and Rare Disease Centre, University of Bari “Aldo Moro”, Bari, Italy \\ "National Institute of Gastroenterology "Saverio de Bellis", Research Hospital, Castellana Grotte Bari, Italy \\ ${ }^{\mathrm{f}}$ Interdisciplinary Department of Medicine (DIM), Section of Dentistry, University of Bari Aldo Moro, Bari, Italy \\ ${ }^{\mathrm{g}}$ Department of Clinical and Experimental Medicine, Psychiatric Unit, University of Foggia, Foggia, Italy \\ ${ }^{\mathrm{h}}$ Otolaryngology Unit, University of Bari Aldo Moro, Italy \\ institute of Neurology, Catholic University of Sacred Heart, Rome, Italy
}

Accepted 8 December 2017

\begin{abstract}
Frailty, a critical intermediate status of the aging process that is at increased risk for negative health-related events, includes physical, cognitive, and psychosocial domains or phenotypes. Cognitive frailty is a condition recently defined by operationalized criteria describing coexisting physical frailty and mild cognitive impairment (MCI), with two proposed subtypes: potentially reversible cognitive frailty (physical frailty/MCI) and reversible cognitive frailty (physical frailty/preMCI subjective cognitive decline). In the present article, we reviewed the framework for the definition, different models, and the current epidemiology of cognitive frailty, also describing neurobiological mechanisms, and exploring the possible prevention of the cognitive frailty progression. Several studies suggested a relevant heterogeneity with prevalence estimates
\end{abstract}

\footnotetext{
${ }^{1}$ These authors contributed equally to this work.

${ }^{*}$ Correspondence to: Francesco Panza, MD, PhD, Geriatric Unit and Laboratory of Gerontology and Geriatrics, Department of Medical Sciences, IRCCS “Casa Sollievo della Sofferenza”, San Giovanni Rotondo, Foggia, Italy and Neurodegenerative Disease Unit, Department of Basic Medicine, Neuroscience, and Sense Organs, University of Bari Aldo Moro, Bari, Italy and Depart-
}

ment of Clinical Research in Neurology, University of Bari Aldo Moro, "Pia Fondazione Cardinale G. Panico", Tricase, Lecce, Italy. Tel./Fax: +390882 410271; E-mail: geriat.dot@uniba.it and Madia Lozupone, MD, Neurodegenerative Disease Unit, Department of Basic Medicine, Neuroscience, and Sense Organs, University of Bari Aldo Moro, Bari, Italy. E-mail: madia.lozupone@ gmail.com. 
ranging 1.0-22.0\% (10.7-22.0\% in clinical-based settings and 1.0-4.4\% in population-based settings). Cross-sectional and longitudinal population-based studies showed that different cognitive frailty models may be associated with increased risk of functional disability, worsened quality of life, hospitalization, mortality, incidence of dementia, vascular dementia, and neurocognitive disorders. The operationalization of clinical constructs based on cognitive impairment related to physical causes (physical frailty, motor function decline, or other physical factors) appears to be interesting for dementia secondary prevention given the increased risk for progression to dementia of these clinical entities. Multidomain interventions have the potential to be effective in preventing cognitive frailty. In the near future, we need to establish more reliable clinical and research criteria, using different operational definitions for frailty and cognitive impairment, and useful clinical, biological, and imaging markers to implement intervention programs targeted to improve frailty, so preventing also late-life cognitive disorders.

Keywords: Alzheimer's disease, biomarkers, dementia, frailty, lifestyle, mild cognitive impairment, nutrition, prevention, subjective cognitive decline, vascular dementia

\section{INTRODUCTION}

Chronic diseases accelerate aging, thereby diminishing the body's adaptation via the relevant stress responses. In older age, multiple subclinical and agerelated comorbidities and the occurrence of stressors (i.e., illness, injury, psychosocial stress) may exacerbate functional decline in the physiological reserves of several systems, which would then result in a homeostatic imbalance or frailty. In 1965, Bernard Isaacs coined the term "geriatric giants", including in this definition syndromes such as immobility, instability and falls, incontinence (urinary and fecal), and intellectual impairment (delirium and dementia) [1]. Over the subsequent five decades, the modern "geriatric giants" has evolved encompassing the four new syndromes of frailty, sarcopenia, the anorexia of aging, and cognitive impairment [2]. The term 'frailty' has been used scientifically since at least 1979, when Vaupel and colleagues employed it to describe variability in life expectancy [3]. In geriatric medicine, frailty was a condition at higher risk for adverse health-related outcomes, including falls, disability, hospitalizations, and mortality. Therefore, frailty is a critical intermediate status of the aging process and the development of frailty is a novel perspective to health and wellness that gained considerable attention as a stronger indicator than chronologic aging of biological aging and survival $[4,5]$. Therefore, frailty is a modern geriatric giant and the recent Asia-Pacific Clinical Practice Guidelines for the Management of Frailty [6] and the International Association of Gerontology and Geriatrics (IAGG) Frailty Consensus [4] defined frailty as a reduced strength and physiologic malfunctioning that increases an individual's susceptibility to increased dependency, vulnerability, and death. After more than twenty years of intensive clinical research, no accepted reference standard, universal criteria, or consensus operational definition has been reached nor have definitive assessment tools or biological markers been established to identify frailty, and extensive international efforts are underway to identify the means of optimal measurement. Among over forty operational definitions proposed, three major approaches to defining frailty exist. The first was the concept of physical frailty phenotype, probably the most popular model of this condition and offering an operational definition based on an assumed state of negative energy balance, sarcopenia, diminished strength, and low tolerance for exertion. This phenotype or biological model was originally operationalized using the Cardiovascular Health Study (CHS) database, using five practically measurable items: exhaustion, involuntary weight loss, weak grip strength, slow walking speed, and low energy expenditure, and the number of positive items defined the individual as frail $(\geq 3)$, prefrail (1-2), and robust (none) [7]. Cognition and mood were excluded. An alternative and potentially complementary definition of frailty is the so-called deficit accumulation model, incorporating a large number of candidate factors ranging from disease states, symptoms, signs, to abnormal laboratory values. When combined and divided by the total number of deficits, these yield a frailty index [8,9]. Differently from the frailty phenotype, the deficit accumulation model of frailty is based on the results of a previous comprehensive geriatric assessment (CGA) [10], defining a status of biological aging and including cognitive, emotional, motivational, and social characteristics given the multidimensional and multisystem nature of biological changes underpinning the frail condition. The third approach to frailty deserving special attention is the biopsychosocial model $[11,12]$, mixing physical and psychosocial domains, 
and expanding the construct of frailty toward social sciences.

\section{DIFFERENT FRAILTY PHENOTYPES}

Frailty might be a con sequence of increasing entropy and gradual disorganization of the body, in a way that is similar to dementia [13]; therefore, it may be difficult to understand when frailty from a risk-state becomes a true pathological state. Frailty is currently considered as "primary" or "pre-clinical" when the state is not associated directly with a specific disease, or when there is no substantial disability [14]. In this context, the physical phenotype seems more appropriate to define primary frailty [7]. In contrast, frailty is considered "secondary" or "clinical" when it is associated with known comorbidity such as dementia or overt cardiovascular disease and/or disability [15]. Therefore, this condition appears to be better defined with the model linking frailty to the accumulation of deficits $[8,9]$. While most of the available definitions have privileged the physical dimension of frailty, other factors such as nutrition [16], depression [17], and cognition [18] may also influence the status of this syndrome in older age. The multidimensional nature of the deficit accumulation model and the biopsychosocial model prompted an approach to frailty based on different pathogeneses, and this heterogeneous clinical syndrome may include physical, cognitive, social, and psychological domains [2]. Therefore, the principal phenotypes are physical frailty [7], cognitive frailty [19], social frailty [20], and psychological frailty [21], this last encompassing motivational and mood components, i.e., the recently proposed depressive frail phenotype [22]. Among these phenotypes, social frailty is the most unexplored concept, while the identification of social frailty models could be a further step for a more global appreciation of frailty, taking into account the role played by the socioeconomic context in determining the vulnerability status in older age. Social frailty can be defined as a continuum of being at risk of losing, or having lost, social and general resources, activities, or abilities that are important for fulfilling one or more basic social needs during the lifespan [20]. In population-based studies, social frailty has been operationalized with single questions or items from functional and depressive symptom scales or health checklists [23, 24]. In this setting, social frailty status may be predictive of mortality [23], disability $[24,25]$, and cognitive outcomes [24] in older age. Psychological frailty, encompassing the concepts of mood and motivational frailty, also suggests a parallel to physical frailty in the domains of mood, a relatively persistent state of emotion such as depression, fear, anxiety, or anger, and motivation, the drive toward a goal, or lack thereof (apathy), that is linked to mood but can be largely independent of it as is noted, for example, in nondepressed individuals with dementia [20]. In particular, depression and physical frailty share several clinical characteristics such as loss of energy, fatigability, poor sleep, and reduced interest [20]. Moreover, there was a bidirectional association between depression and physical frailty in later life [17], although have not explored the possibility of the existence of a primary, intrinsic vulnerability to emotional stressors with age that might signal mood frailty, a possible precursor to depression and its negative health outcomes [20]. Very recently, it was proposed a depressive frail phenotype as a highrisk morbidity and mortality syndrome of later life, reassembling the confluence between depression and frailty [22]. This model hypothesized that characteristics of frailty in adults with late-life depression may represent the clinical manifestation of greater biological aging, exposing elders to deleterious trajectories [22]. Finally, notwithstanding the clinical or biological characterization of these different frailty phenotypes, it remains unclear whether people who suffer from multiple frailty phenotypes are at greater risk for negative outcomes of frailty. As deficits in the physical dimension are particularly known to be important predictors for adverse health-related outcomes, this phenotype may be taken as reference [26]. However, whether physically frail older people are more at risk for developing adverse outcomes if they also suffer from cognitive, social, or psychological frailty remains an open issue [27]. Among these different phenotypes, cognitive frailty is increasingly recognized as a fundamental determinant of the individual's vulnerability and resilience to stressors [28]. The present narrative review article aimed to refine the framework for the definition, different models, relevant screening and diagnostic tools, biomarkers, and the current epidemiology of cognitive frailty, also describing neurobiological mechanisms underlying this novel construct, and exploring the possible prevention of the cognitive frailty progression.

\section{COGNITIVE FRAILTY: AN EMERGING CONCEPT}

A recent and growing body of epidemiological evidence suggested that frailty may increase the risk of 
future cognitive decline and that cognitive impairment may increase the risk of frailty suggesting that cognition and frailty may interact in advancing aging $[18,29,30]$. Several studies examined frailty and cognitive impairment as both antecedents and outcomes [31]. The mutual influences between frailty and impaired cognition have been discussed, including the proposed construct of cognitive frailty. In fact, while physical frailty phenotype is a widely recognized problem in older age, only in recent years has the term cognitive frailty emerged in the literature. In 2001, this term was incidentally used by PaganiniHill and colleagues in a study on Clock Drawing Test (CDT) performance and its association with potential protective and risk factors for Alzheimer's disease (AD) in an older cohort [32]. In 2004, the term cognitive frailty has been used as a general descriptor for cognitive impairment occurring as people reach advanced age, or to refer to cognitive disturbances or predementia occurring in association with other medical conditions [33]. However, only in 2006, cognitive frailty was used as a clinical label to indicate a particular state of cognitive vulnerability in mild cognitive impairment (MCI) and other similar clinical entities exposed to vascular risk factors and with a subsequent increased progression to dementia, particularly vascular dementia (VaD) [34]. In 2013, a consensus on the definition of cognitive frailty was reached by an international consensus group from the International Academy of Nutrition and Aging (IANA) and the IAGG [35]. The proposed diagnostic criteria for this novel and heterogeneous clinical agerelated condition included the simultaneous presence of physical frailty operationalized with the CHS phenotypic/biological model and cognitive impairment diagnosed with a Clinical Dementia Rating (CDR) scale of 0.5 (i.e., questionable dementia, a stage of the dementia continuum similar to $\mathrm{MCI}$ ) without a concurrent diagnosis of AD or other dementias [35] (Table 1). Therefore, cognitive frailty is held to be a combination of MCI and physical frailty, which is defined by the five classical features of CHS, three of which (i.e., reduced physical activity, motor slowing, weight loss) are known to be risk factors for dementia [35].

\section{The potential for reversibility of different cognitive frailty models}

Among frailty phenotypes, cognitive frailty has been proposed as a clinical entity with cognitive impairment related to physical causes, with a potential reversibility, and as an important target of secondary intervention in early or asymptomatic stage of dementia [36]. In 2015, the first systematic review on this intriguing topic suggested that frailty indexes based on a deficit accumulation model were associated in hospital- and population-based studies with late-life cognitive impairment and decline, incident dementia, and AD [37]. Furthermore, physical frailty models may also be associated with late-life cognitive impairment and decline, incident $\mathrm{AD}$ and $\mathrm{MCI}, \mathrm{VaD}$, non-AD dementias, and $\mathrm{AD}$ pathology in older persons with and without dementia, so giving support to identify cognitive frailty as a new clinical condition [37]. Recently, a meta-analysis suggested that the frailty was a significant predictor of $\mathrm{AD}, \mathrm{VaD}$, and all dementia among community-dwelling older people, with frail women at higher risk of incident AD than frail men [38].

The potential for reversibility of frailty and its different phenotypes suggests that these clinical constructs may be important secondary targets for the prevention of dependency and other negative outcomes in older age [19]. More recently, in an attempt to refine the framework for the definition and potential mechanisms of cognitive frailty, two subtypes for this clinical construct were proposed: "potentially reversible" cognitive frailty and "reversible" cognitive frailty [19, 39] (Table 1). The physical factors should be physical prefrailty and frailty for both the subtypes. The cognitive impairment of potentially reversible cognitive frailty should be MCI $(\mathrm{CDR}=0.5)$, while the cognitive impairment of reversible cognitive frailty should be pre-MCI subjective cognitive decline $(\mathrm{SCD})(\mathrm{CDR}=0)$, as recently formulated by the Subjective Cognitive Decline Initiative (SCD-I) Working Group that proposed a basic conceptual framework for the study of the common concepts of SCD, pre-MCI SCD, and SCD in preclinical AD [40].

\section{Screening and diagnostic tools defining cognitive frailty}

The current working definitions of cognitive frailty $[20,34,38]$ may provide a valuable starting point for the development of a coherent operational definition and for future studies of cognitive frailty. While the physical factors of cognitive frailty were diagnosed with the physical frailty model operationalized with the CHS criteria, the cognitive pattern of this clinical construct was not clearly characterized. The studies published so far mostly adopted 
Table 1

Different operational models of cognitive frailty for older individuals without Alzheimer's disease or other forms of dementia

\begin{tabular}{|c|c|c|c|}
\hline \multirow[t]{2}{*}{ Cognitive Status } & \multicolumn{3}{|c|}{ Physical Status } \\
\hline & $\begin{array}{l}\text { Robust } \\
\text { (none positive item) }\end{array}$ & $\begin{array}{l}\text { Pre-physical frailty } \\
\text { (1-2 positive items) }\end{array}$ & $\begin{array}{l}\text { Physical frailty } \\
\text { ( } \geq 3 \text { positive items) }\end{array}$ \\
\hline & $\begin{array}{l}\text { CHS physical frailty items } \\
\text { Exhaustion - Weight loss - } \\
\text { expenditure }\end{array}$ & Weak grip strength - Slo & w walking speed - Low energy \\
\hline $\begin{array}{l}\text { Normal } \\
\text { Pre-clinical stage } \\
\text { (positive } \\
\text { biomarkers and/or } \\
\text { pre-MCI SCD) }\end{array}$ & $\begin{array}{l}\text { Robust } \\
\text { Pre-clinical stage }\end{array}$ & $\begin{array}{l}\text { Pre-physical frailty } \\
\text { Reversible cognitive } \\
\text { frailty }\end{array}$ & $\begin{array}{l}\text { Physical frailty } \\
\text { Reversible cognitive } \\
\text { frailty }\end{array}$ \\
\hline MCI (CDR: 0.5) & MCI & $\begin{array}{l}\text { Potentially reversible } \\
\text { cognitive frailty }\end{array}$ & $\begin{array}{l}\text { Potentially reversible } \\
\text { cognitive frailty } \\
\text { IANA/IAGG model } \\
\text { of cognitive frailty }\end{array}$ \\
\hline
\end{tabular}

CHS, Cardiovascular Health Study; MCI, mild cognitive impairment; SCD, subjective cognitive decline; CDR, Clinical Dementia Rating scale; IANA/IAGG, International Academy of Nutrition and Aging/International Association of Gerontology and Geriatrics.

different operational definitions of cognitive frailty, but a lesser degree of heterogeneity was instead observed for the definition of physical frailty, almost exclusively operationalized by considering the CHS criteria [7]. On the contrary, a relevant heterogeneity was observed with regard to the assessment of cognitive functioning and the definition of cognitive impairment. The panel of experts of the IANA-IAGG suggested that all frail subjects should perform a comprehensive cognitive assessment exploring memory performance as well as other cognitive functions, in particular executive functions with Montreal Cognitive Assessment test (MoCA), Mini-Mental State Examination (MMSE), Alzheimer's Disease Assessment Scale-cognitive subscale (ADAS-Cog), and speed processing tests to identify cognitive frailty [35]. The objective was to exclude the diagnosis of AD. However, the optimal measures or combination of measures to accurately detect cognitive frailty in the clinical setting are unclear [40], and in 2013, the IANA-IAGG consensus described a hypothetical condition without clinical findings available to support it. After four years of clinical research on this novel construct, two very recent review articles investigated the body of evidence on the optimal measures for detecting cognitive frailty in clinical populations of older adults [41, 42]. In the first review, in the 49 identified studies, cognitive frailty was mainly characterized by deficits in global cognitive function and was measured using cognitive screening instruments such as the MMSE, the CDT, Mini-Cog measures, or a series of cognitive tests (measuring language, executive function, spatial ability, and verbal and nonverbal memory) [41]. Additionally, fifteen studies quantified cognitive frailty using selfreport of memory problems, and only three studies included indicators to reflect specific aspects of cognitive function, such as neuromotor processing, verbal fluency, and executive function [41]. Another integrative review, focused only on studies using the IANA-IAGG cognitive frailty construct [35], identified eleven reports, of which two studies assessed global cognition with the MMSE, four used the MMSE and domain specific neuropsychiatric testing, three used only domain neuropsychiatric testing, and one assessed global cognition with both the MMSE and MoCA with domain specific neuropsychiatric testing [42]. While this review confirmed the link between physical frailty and cognition with developing validity to support distinct relationships between components of physical frailty and cognitive decline [42], inconsistencies in reporting of reliability, validity, and heterogeneity in the measurements and operational definition for cognitive frailty suggested further research to establish a commonly accepted operational definition and develop psychometrically appropriate clinical measures for this novel clinical construct. Finally, recent findings from the Multidomain Alzheimer Disease Preventive Trial (MAPT) suggested that the cognitive profile of cognitive frail individuals significantly differed from individuals with cognitive impairment and without physical frailty, scoring worse at executive and attention tests, and suggesting a pattern similar to that of multiple-domain amnestic MCI [43]. Furthermore, cognitive performance of subjects with 3 criteria or 
more of the frailty phenotype are cognitively more impaired than subjects with only one [43].

\section{Biomarkers of cognitive frailty}

The IANA-IAGG consensus suggested some biomarkers that may be able to capture both the risk of future physical and cognitive declines, such as inflammatory markers [i.e., C-reactive protein (CRP) and interleukin (IL)-6] [35]. A recent population-based study with findings from the Italian Longitudinal Study on Aging (ILSA) confirmed the role of inflammatory state in a model of potentially reversible cognitive frailty that had a significant additional predictive effect on the risk of disability than the single conditions of frailty or MCI in older individuals without dementia and with elevated inflammation [44]. However, biomarkers predictive of both types of decline may not be particularly useful in differentiating whether a person is at higher risk of a future physical rather than a cognitive decline or vice versa [35]. Other biomarkers may better serve at estimating the specific risk for one single domain, i.e., markers of amyloid- $\beta(\mathrm{A} \beta)$ accumulation and neurodegeneration or neuronal injury on which were mainly based the National Institute on Aging-Alzheimer's Association (NIA-AA) research clinical criteria for preclinical stages of AD [45] and MCI due to AD [46] and the apolipoprotein $\mathrm{E}$ (APOE) $\varepsilon 4$ genotype that is closely related to the development of dementia and $\mathrm{AD}$ [47]. According to the different types of cognitive impairment, cognitive frailty was suggested to divide into reversible and potentially reversible cognitive frailty [19, 39]. The reversible cognitive impairment may correspond to pre-MCI stage $(\mathrm{CDR}=0)$ which may be preclinical AD or other pre-MCI due to non$\mathrm{AD}$ with $\mathrm{SCD}$. The potential reversible cognitive impairment may correspond to $\mathrm{MCI}(\mathrm{CDR}=0.5)$, a predementia state. Subjects with reversible cognitive frailty and no biomarker evidence of AD pathology could be individuals with normal cognitive aging or undetectable preclinical AD [48]. Reversible cognitive frail subjects with cerebral amyloidosis $(\mathrm{A} \beta$ accumulation on positron emission tomography amyloid imaging) could be individuals with preclinical $\mathrm{AD}$, early stage of dementia with Lewy bodies, or $\mathrm{VaD}$ [48]. Reversible cognitive frail subjects with evidence of neurodegeneration or neuronal injury plus amyloidosis could be individuals with preclinical $\mathrm{AD}$, while without amyloidosis could be individuals with normal cognitive aging or suspected non-AD dementias [48]. Therefore, reversible cognitive and functional damages as defined in these models of cognitive frailty could be an optimal target for a secondary prevention of cognitive and functional impairment also for AD [36], hopefully including in future preventive trials biomarker-positive reversible cognitive frailty individuals.

\section{CURRENT EPIDEMIOLOGY OF COGNITIVE FRAILTY}

From 2013, date of the IANA-IAGG consensus on cognitive frailty, and in the last two years only, a relevant number of studies have proposed original epidemiological findings strictly using the proposed definition of this novel clinical construct on individuals in older age [43, 44, 49-55]. In particular, there were three cross-sectional studies, and of these, one report described the MAPT findings on the neuropsychological profile of cognitive frail subjects [43], the second evaluated the association of cognitive frailty with functional independence [49], and the third was specifically aimed at estimating the prevalence of this condition [50]. Furthermore, five longitudinal studies have explored the association between cognitive frailty and adverse health-related outcomes (mortality, hospitalization, quality of life, and loss of functional independence) $[44,51,54]$ and cognitive-related outcomes such as progression to dementia/neurocognitive disorders [44, 52-54].

\section{Prevalence}

The cumulative evidence coming from these first eight studies estimating the prevalence of cognitive frailty suggested a relevant heterogeneity with estimates ranging from $1.0 \%$ to $22.0 \%$ [43, 44, 49-54] (Table 2). A series of factors may contribute to this wide variability, i.e., the different models of cognitive frailty, the operationalization of the two components of cognitive frailty (physical frailty and cognitive impairment), the age and gender of the samples, and the settings of the different studies. This last factor appeared to be the strongest determinant of the different estimates, with clinical-based studies obtaining higher prevalence of cognitive frailty $(10.7 \%-22.0 \%)$ $[43,52]$ compared with population-based studies (ranging from $1.0 \%$ to $4.4 \%$ ) [44, 49, 50, 52-54]. With regard to age and gender, in population-based settings, findings on 1575 older subjects from the Singapore Longitudinal Ageing Studies (SLAS), suggested that the prevalence of a potentially reversible cognitive frailty model (coexisting physical frailty 
Table 2

Principal clinical- and population-based studies estimating the prevalence of different models of cognitive frailty

\begin{tabular}{|c|c|c|c|c|c|}
\hline Reference & $\begin{array}{l}\text { Study design and } \\
\text { setting }\end{array}$ & $\begin{array}{c}\text { Sample, } \\
\mathrm{n}\end{array}$ & $\begin{array}{c}\text { Age, } \\
\text { mean } \pm \mathrm{SD}\end{array}$ & Operationalization of cognitive frailty & Prevalence, $\%$ \\
\hline \multicolumn{6}{|c|}{ Cross-sectional studies } \\
\hline Delrieu et al., [43] & $\begin{array}{l}\text { Cross-sectional clinical-based } \\
\text { study; the Multidomain } \\
\text { Alzheimer Disease } \\
\text { Preventive Trial }\end{array}$ & 1,617 & $75.4 \pm 4.5$ & $\begin{array}{l}\text { Potentially reversible cognitive frailty defined } \\
\text { with the presence of physical frailty } \\
\text { operationalized with the modified CHS } \\
\text { criteria ( } \geq 1 \text { criterion) and cognition assessed } \\
\text { using a CDR of } 0.5 \text {, and absence of concurrent } \\
\text { dementia or neurodegenerative conditions } \\
\text { clinically determined }\end{array}$ & 22.0 \\
\hline $\begin{array}{l}\text { Shimada et al., } \\
\text { [49] }\end{array}$ & $\begin{array}{l}\text { Cross-sectional } \\
\text { population-based study; the } \\
\text { National Center for Geriatrics } \\
\text { and Gerontology-Study of } \\
\text { Geriatric Syndromes } \\
\text { database }\end{array}$ & 8,864 & $73.4 \pm 0.3$ & $\begin{array}{l}\text { Potentially reversible cognitive frailty defined } \\
\text { with the presence of physical frailty } \\
\text { operationalized with the modified CHS } \\
\text { criteria ( }>3 \text { criteria) and cognition assessed } \\
\text { using the National Center for Geriatrics and } \\
\text { Gerontology-Functional Assessment Tool, and } \\
\text { absence of concurrent dementia or } \\
\text { neurodegenerative conditions clinically } \\
\text { determined }\end{array}$ & 1.2 \\
\hline $\begin{array}{l}\text { Roppolo et al., } \\
\text { [50] }\end{array}$ & $\begin{array}{l}\text { Cross-sectional } \\
\text { population-based study }\end{array}$ & 594 & $73.6 \pm 5.8$ & $\begin{array}{l}\text { Potentially reversible cognitive frailty defined } \\
\text { with the presence of physical frailty } \\
\text { operationalized with the modified CHS } \\
\text { criteria ( }>1 \text { criterion) and cognition assessed } \\
\text { using a score }<25 \text { on the MMSE. Not } \\
\text { specified the exclusion of concurrent dementia } \\
\text { or neurodegenerative conditions }\end{array}$ & 4.4 \\
\hline \multicolumn{6}{|l|}{ Longitudinal studies } \\
\hline $\begin{array}{l}\text { Montero-Odasso } \\
\text { et al., } 2016 \text { [52] }\end{array}$ & $\begin{array}{l}\text { Longitudinal clinical-based } \\
\text { study with } 5 \text { years of } \\
\text { follow-up; the Gait and Brain } \\
\text { Study }\end{array}$ & 255 & $73.6 \pm 8.6$ & $\begin{array}{l}\text { Potentially reversible cognitive frailty was } \\
\text { defined with the presence of physical frailty } \\
\text { operationalized with the modified CHS } \\
\text { criteria ( } \geq 3 \text { criteria) and cognition assessed } \\
\text { using the MoCA score below } 26 \text { and a CDR of } \\
0.5 \text {, and absence of concurrent dementia. Gait } \\
\text { was assessed using an electronic walkway }\end{array}$ & 10.7 \\
\hline Feng et al., [53] & $\begin{array}{l}\text { Longitudinal population-based } \\
\text { study with } 3 \text { years of } \\
\text { follow-up; the Singapore } \\
\text { Longitudinal Ageing Studies }\end{array}$ & 1575 & $66.0 \pm 7.6$ & $\begin{array}{l}\text { Potentially reversible cognitive frailty was } \\
\text { defined with the presence of physical frailty } \\
\text { operationalized with the modified CHS } \\
\text { criteria ( } \geq 3 \text { criteria) and cognition assessed } \\
\text { with the Chinese version MMSE, and absence } \\
\text { of concurrent dementia }\end{array}$ & 1.0 \\
\hline Feng et al., [51] & $\begin{array}{l}\text { Longitudinal population-based } \\
\text { study with } 3 \text { years of } \\
\text { follow-up; the Singapore } \\
\text { Longitudinal Ageing Studies }\end{array}$ & 2375 & $65.8 \pm 7.5$ & $\begin{array}{l}\text { Potentially reversible cognitive frailty was } \\
\text { defined with the presence of physical frailty } \\
\text { operationalized with the modified CHS } \\
\text { criteria ( } \geq 3 \text { criteria) and cognition assessed } \\
\text { with the Chinese version MMSE, and absence } \\
\text { of concurrent dementia }\end{array}$ & 1.8 \\
\hline $\begin{array}{l}\text { Solfrizzi et al., } \\
\text { [44] }\end{array}$ & $\begin{array}{l}\text { Longitudinal population-based } \\
\text { study with } 3.5 \text { years of } \\
\text { median follow-up; the Italian } \\
\text { Longitudinal Study on Aging }\end{array}$ & 2373 & $76.7 \pm 4.4$ & $\begin{array}{l}\text { Potentially reversible cognitive frailty was } \\
\text { defined with the presence of physical frailty } \\
\text { with a modified phenotype operationalized } \\
\text { with the modified CHS criteria ( } \geq 3 \text { criteria), } \\
\text { MCI diagnosed with modified Petersen } \\
\text { criteria, and absence of concurrent dementia }\end{array}$ & 1.0 \\
\hline $\begin{array}{l}\text { Solfrizzi et al., } \\
\text { [54] }\end{array}$ & $\begin{array}{l}\text { Longitudinal population-based } \\
\text { study with } 3.5 \text { and } 7 \text { years of } \\
\text { median follow-up; the Italian } \\
\text { Longitudinal Study on Aging }\end{array}$ & 2150 & $73.2 \pm 5.6$ & $\begin{array}{l}\text { Reversible cognitive frailty was defined with the } \\
\text { presence of physical frailty with a modified } \\
\text { phenotype operationalized with the modified } \\
\text { CHS criteria ( } \geq 3 \text { criteria), pre-MCI SCD, } \\
\text { diagnosed with a self-report measure based on } \\
\text { item } 14 \text { of the } 30 \text {-item GDS, and absence of } \\
\text { concurrent dementia }\end{array}$ & 2.5 \\
\hline
\end{tabular}

CHS, Cardiovascular Health Study; CDR, Clinical Dementia Rating scale; MoCA, Montreal Cognitive Assessment; MMSE, Mini-Mental State Examination; pre-MCI SCD, pre-mild cognitive impairment subjective cognitive decline; GDS, Geriatric Depression Scale. 
and cognitive impairment operationalized with a score $<23$ on the Chinese version of the MMSE) was $1 \%$ [95\% confidence interval (CI): $0.5-1.4]$ but was higher among participants aged 75 and older (5.0\%; 95\% CI:1.8-8.1) [53], although, the prevalence increased to $1.8 \%$ when estimated on 2375 older individuals from the SLAS [51]. These data were confirmed from the ILSA, in which the prevalence of potentially reversible cognitive frailty was 1.0 , increasing with class of age, and more represented (about twice) in women than in men [44]. Other Japanese findings from the National Center for Geriatrics and Gerontology-Study of Geriatric Syndromes database confirmed a prevalence rate of $1.2 \%$ of a potentially reversible cognitive frailty model [49]. However, in 594 Italian community-dwelling older adults, the prevalence rate of a potentially reversible cognitive frailty model (physical frailty and cognitive impairment operationalized with a score $<25$ on the MMSE) was $4.4 \%$, and this higher estimate may be explained by the general higher age in this sample [50]. With regard to the cognitive frailty model used, in population based settings, almost all the studies reviewed adopted a model of potentially reversible cognitive frailty $[44,49-51$, 53], while, at the best of our knowledge, only one large population-based study estimated a model of reversible cognitive frailty (physical frailty plus preMCI SCD) with findings from the ILSA (prevalence: 2.5\%) [54]. Furthermore, the operationalization of physical frailty could influence the prevalence estimates. In fact, a single study adopted at least one CHS criterion for diagnosing physical frailty, so considering as frail also prefrail older subjects, and reporting higher prevalence (prevalence: $22.0 \%$ ) [43], while the remaining studies only slightly modified the original CHS criteria [43, 44, 49-54]. Finally, higher estimates were also obtained in another study not excluding subjects with dementia or other concomitant neurodegenerative conditions (prevalence: $4.4 \%$ ) [50].

\section{Cognitive frailty and adverse health-related outcomes}

Some cross-sectional and longitudinal populationbased studies investigated different cognitive frailty models associated with functional disability, quality of life, hospitalization, and all-cause mortality [44, 49-51, 54] (Table 3), health-related outcomes traditionally linked to different frailty models. Recently, two cross-sectional population-based studies found in individuals with potentially reversible cognitive frailty a higher risk of instrumental activities of daily living limitation (National Center for Geriatrics and Gerontology-Study of Geriatric Syndromes database) [49] and disability [50]. Very recently, data from the ILSA suggested that in older individuals with potentially reversible cognitive frailty and a high level of inflammation, a significant additional predictive effect only on the risk of disability has been found, but not of all-cause mortality [44]. In the same study, over 3.5-year and 7-year followups, older individuals with reversible cognitive frailty showed an increased risk of all-cause mortality [hazard ratio (HR): $1.74,95 \%$ CI: $1.07-2.83$ and HR: 1.39, 95\% CI 1.03-2.00, respectively] [54]. These apparently discrepant findings suggested a different impact of different models of cognitive frailty on the risk of all-cause mortality. Longitudinal data from the SLAS showed that potentially reversible cognitive frailty was associated with an evidently high risk of functional disability, poor quality of life, and mortality, but not of hospitalization [51], giving further support to the previous findings of an impact of cognitive frailty on adverse health-related outcomes in population-base settings.

\section{Cognitive frailty and cognitive-related outcomes}

Four longitudinal population-based studies investigated different cognitive frailty models associated with incidence of dementia, $\mathrm{AD}, \mathrm{VaD}$, and neurocognitive disorders [44, 52-54] (Table 4). In the Singapore Longitudinal Ageing Studies (SLAS), continuous physical frailty score and MMSE score showed significant individual and joint associations with incident mild and major neurocognitive disorder [53]. In this study, potentially reversible cognitive frailty conferred additionally greater risk of incident neurocognitive disorder (mild plus major neurocognitive disorder) [53]. Moreover, very recent findings from the Gait and Brain Study suggested that another model of potentially reversible cognitive frailty (physical frailty plus CDR of 0.5 ) increased incident rate but not risk for progression to dementia, although, the combination of slow gait and objective cognitive impairment, which has been labeled as the Motoric Cognitive Risk syndrome [55], posed the highest risk for progression to dementia when compared with physical frailty and cognitive frailty models [52]. Possible discrepancies in predicting cognitive-related outcomes may arise from different models of cognitive frailty in which cognitive impair- 
Table 3

Principal cross-sectional and longitudinal population-based studies on the association of different cognitive frailty models with adverse health-related outcomes

\begin{tabular}{ll}
\hline Reference & Study design and \\
& setting \\
\hline Cross-sectional studies \\
Shimada et al., & Cross-sectional population-based \\
{$[49]$} & study; the National Center for \\
& Geriatrics and \\
& Gerontology-Study of \\
& Geriatric Syndromes database
\end{tabular}

Roppolo et al., Cross-sectional population-based [50] study

Longitudinal studies

Feng et al., Longitudinal population-based [51] study with 3 years of follow-up; the Singapore Longitudinal Ageing Studies

Adverse health-related outcomes Principal results

IADL status (use of public transportation, shopping, management of finances, and housekeeping)

Disability measured with the Groningen Activity Restriction Scale

Functional disability assessed by self-reported measures of IADL and ADL. QOL measured using the Medical Outcomes Study SF-12 of QOL. Hospitalization and mortality

Disability measured with ADL and all-cause mortality follow-up; the Italian Longitudinal Study on Aging
Solfrizzi et al., Longitudinal population-based [54]

$$
\begin{aligned}
& \text { study with } 3.5 \text { and } 7 \text { years of } \\
& \text { median follow-up; the Italian } \\
& \text { Longitudinal Study on Aging }
\end{aligned}
$$
physical component summary (PCS)

Significant relationships between IADL limitations and physical frailty (OR: 1.24, 95\% CI: 1.01 to 1.52), cognitive impairment (OR: $1.71,95 \%$ CI: 1.39 to 2.11 ), and potentially reversible cognitive frailty (OR: $2.63,95 \%$ CI: 1.74 to 3.97)

Individuals with potentially reversible cognitive frailty showed a higher disability level in comparison to people without cognitive frailty

Individuals with potentially reversible cognitive frailty stood out with 12- to 13-fold increased prevalence and incidence of functional disability, a five- and 27-fold increased prevalence and incidence of low QOL, and a fivefold increased mortality risk. Regarding hospitalization, in cross-sectional and longitudinal analyses, no association across subcategories of physical frailty with and without cognitive impairment were observed

In potentially reversible cognitively frail older individuals with a high inflammatory state has been found a significant additional predictive effect on the risk of disability than in frail/non-MCI individuals, while it has not been found for all-cause mortality. In the potentially reversible cognitive frailty and high inflammatory state group, the predicted number of older subjects disabled was about 461 per thousand persons over a 3.5-year follow-up period

All-cause mortality
Over 3.5-year and 7-year follow-ups, participants with reversible cognitive frailty showed an increased risk of all-cause mortality (HR: 1.74, 95\% CI: 1.07-2.83 and HR: 1.39, 95\% CI 1.03-2.00, respectively). Vascular risk factors and depressive symptoms did not have any effect modifier on the relationship between reversible cognitive frailty and all-cause mortality

IADL, instrumental activities of daily living; ADL, activities of daily living; QOL, quality of life; OR, odds ratio; CI, confidence interval; HR, hazard ratio. 
Table 4

Principal longitudinal population-based studies on the association of different cognitive frailty models with late-life cognitive decline, dementia, Alzheimer's disease (AD), vascular dementia ( $\mathrm{VaD})$ and other cognitive-related outcomes

\begin{tabular}{|c|c|c|c|}
\hline Reference & $\begin{array}{l}\text { Study design and } \\
\text { setting }\end{array}$ & Cognitive-related outcomes & Principal results \\
\hline $\begin{array}{l}\text { Montero-Odasso } \\
\text { et al., [52] }\end{array}$ & $\begin{array}{l}\text { Longitudinal clinical-based study } \\
\text { with } 5 \text { years of follow-up; the Gait } \\
\text { and Brain Study }\end{array}$ & $\begin{array}{l}\text { Cognitive decline operationalized as } \\
\text { a decrease of at least two points in } \\
\text { MoCA scores between baseline } \\
\text { and the last assessment, incidence } \\
\text { of dementia according to DSM-IV } \\
\text { criteria and when CDR progressed } \\
\text { to one or higher }\end{array}$ & $\begin{array}{l}\text { The combination of slow gait and } \\
\text { objective cognitive impairment } \\
\text { posed the highest risk for } \\
\text { progression to dementia (HR: } 35.9 \text {, } \\
\text { 95\% CI: } 4.0-319.2 \text { ) when } \\
\text { compared with physical frailty and } \\
\text { potentially cognitive frailty models }\end{array}$ \\
\hline Feng et al., [53] & $\begin{array}{l}\text { Longitudinal population-based study } \\
\text { with } 3 \text { years of follow-up; the } \\
\text { Singapore Longitudinal Ageing } \\
\text { Studies }\end{array}$ & $\begin{array}{l}\text { Incidence of neurocognitive disorder } \\
\text { according to DSM- } 5 \text { criteria }\end{array}$ & $\begin{array}{l}\text { Continuous physical frailty score and } \\
\text { MMSE score showed significant } \\
\text { individual and joint associations } \\
\text { with incident mild and major } \\
\text { neurocognitive disorder, and } \\
\text { potentially reversible cognitive } \\
\text { frailty conferred additionally } \\
\text { greater risk of incident } \\
\text { neurocognitive disorder (mild plus } \\
\text { major neurocognitive disorder) }\end{array}$ \\
\hline Solfrizzi et al., [44] & $\begin{array}{l}\text { Longitudinal population-based study } \\
\text { with } 3.5 \text { years of median } \\
\text { follow-up; } 1575 \text { older individuals } \\
\text { from the ILSA }\end{array}$ & $\begin{array}{l}\text { Incidence of dementia diagnosed } \\
\text { with the DSM-III-R, AD diagnosed } \\
\text { with the NINCDS-ADRDA } \\
\text { criteria, VaD diagnosed with the } \\
\text { NINDS-AIREN criteria }\end{array}$ & $\begin{array}{l}\text { These findings did not support a } \\
\text { predictive role of a potentially } \\
\text { reversible cognitive frailty model } \\
\text { for the development of incident } \\
\text { dementia compared with physical } \\
\text { frailty or MCI alone }\end{array}$ \\
\hline Solfrizzi et al., [54] & $\begin{array}{l}\text { Longitudinal population-based study } \\
\text { with } 3.5 \text { and } 7 \text { years of median } \\
\text { follow-up; } 2150 \text { older individuals } \\
\text { from the ILSA }\end{array}$ & $\begin{array}{l}\text { Incidence of dementia diagnosed } \\
\text { with the DSM-III-R, AD diagnosed } \\
\text { with the NINCDS-ADRDA } \\
\text { criteria, VaD diagnosed with the } \\
\text { NINDS-AIREN criteria }\end{array}$ & $\begin{array}{l}\text { Over a } 3.5 \text {-year follow-up, } \\
\text { participants with reversible } \\
\text { cognitive frailty showed an } \\
\text { increased risk of overall dementia } \\
\text { (HR: } 2.30,95 \% \text { CI: } 1.02-5.18] \text {, } \\
\text { particularly VaD (HR: } 6.67,95 \% \\
\text { CI } 2.11-20.99 \text { ). Over a } 7 \text {-year } \\
\text { follow-up, participants with } \\
\text { reversible cognitive frailty showed } \\
\text { an increased risk of overall } \\
\text { dementia (HR: } 2.12,95 \% \mathrm{CI} \text { : } \\
1.12-4.03 \text { ), particularly VaD (HR: } \\
6.85,95 \% \text { CI (3.16-14.83). } \\
\text { Vascular risk factors and depressive } \\
\text { symptoms did not have any effect } \\
\text { modifier on the relationship } \\
\text { between reversible cognitive frailty } \\
\text { and incident dementia }\end{array}$ \\
\hline
\end{tabular}

MoCA = Montreal Cognitive Assessment; DSM-IV, Diagnostic and Statistical Manual of Mental Disorders-IV; CDR, Clinical Dementia Rating scale; HR, hazard ratio; CI, confidence interval; DSM-5, Diagnostic and Statistical Manual of Mental Disorders-5; MMSE, MiniMental State Examination; DSM-III-R, Diagnostic and Statistical Manual of Mental Disorders-III revised; NINCDS-ADRDA, National Institute of Neurological and Communicative Disorders and Stroke-Alzheimer's Disease and Related Disorders Association; NINDS-AIREN, National Institute of Neurological Disorders and Stroke-Association Internationale pour la Recherche et l'Enseignement en Neurosciences; MCI, mild cognitive impairment.

ment may be operationalized in different ways. In fact, findings from the ILSA did not support a predictive role of a potentially reversible cognitive frailty model (physical frailty plus MCI) for the development of incident dementia compared with physical frailty or MCI alone [44]. However, other findings coming from the ILSA suggested that a model of reversible cognitive frailty (physical frailty plus preMCI SCD) was a short- and long-term predictor of overall dementia, particularly VaD [54]. In observational studies like the ILSA, in extreme cases, could be of interest to verify that an interaction may reverse the relationship between the risk factor and the outcome. Therefore, it was hypothesized that the role of vascular factors and/or depressive symptoms as effect modifiers could change the risk of dementia and all-cause mortality linked to the presence of reversible cognitive frailty. In particular, trying 
to support the reversibility of this new clinical construct, it was focused on the group of people without these risk factors as a proxy of optimal management of these factors. In the ILSA, the absence of vascular risk factors and depressive symptoms did not modify the predictive role of reversible cognitive frailty on these outcomes [54]. Probably, the identification of reversibility due to several possible interventions could be possible designing specific randomized controlled trials (RCTs) on cognitive frail older individuals.

\section{POSSIBLE NEUROBIOLOGICAL MECHANISMS UNDERLYING COGNITIVE FRAILTY}

From a pathophysiological point of view, the etiology of the cognitive-frailty association appeared to be multifactorial and several mediators or possible pathways have been suggested to explain these links and hormonal and inflammatory processes, together with nutritional, vascular, neuropathological, and metabolic influences may be of major relevance [19, 29, 37, 39, 40, 56-58]. However, given that experimental evidence is lacking, other questions may address the underlying mechanisms and determine which is the most relevant component among the suggested mediators between frailty and cognition. The common consequences of aging may have an impact on age-related conditions such as physical frailty and cognitive decline. The common aging mechanisms, such as nutrition sensing signals, p53 activation, and subsequent telomere deletion and DNA damage, result in the physiological reserve declines of different organs. The long-term chronic stressor overload further accelerates the physiological reserve declines. The different vulnerability of multiple organs, or different structures in same organ, such as brain, results in function-related homeostatic failure, and different phenotypes/diseases, physical frailty, or cognitive frailty $[19,59]$. These different mechanisms are not mutually exclusive, highlighting the need for further studies to better explicate the neurobiological basis of cognitive frailty.

\section{Vascular risk factors and diseases}

The contribution of cardiovascular dysfunction (congestive heart failure, myocardial infarction, peripheral arterial diseases, diabetes mellitus, and hypertension) to cognitive frailty in older adults is uncertain. Cardiovascular risk factors and common vascular diseases have been related to both frailty and cognitive impairment [34]. Physical frailty may be a prodromal stage of $\mathrm{VaD}[60,61]$ and was clearly related to subclinical vascular biomarkers and higher degree of infarct-like lesions in the brain [62]. Furthermore, the suggested association between physical frailty and increased risk of incident $\mathrm{AD}$ [38] may be explained by the underlying increased risk of stroke and cerebrovascular disease. The lesions most evidently linking cognitive decline with frailty are leukoaraiosis [white matter hyperintensities (WMHs)] reflecting chronic blood flow reduction [63]. WMH are frequently associated with vascular disease (i.e., hypertension, diabetes, smoking, and cardiovascular disease). Abnormalities of cardiac structure and function may be independently associated with frailty, showing the greatest association with frailty among several other organ systems, i.e., vascular, pulmonary, renal, hematologic, and adipose systems [64]. Conversely, the findings from the ILSA suggested that the association between reversible cognitive frailty and $\mathrm{VaD}$ persisted in analyses after controlling for vascular risk factors and diseases [54]. Probably, the identification and intervention on vascular risk factors should be done earlier to estimate a positive effect on still unclear possible reverse processes.

\section{Sarcopenia}

Biomarkers of physical frailty, particularly sarcopenia, should predict early cognitive decline. Sarcopenia, an age-related decline in skeletal muscle mass and muscle function $[65,66]$ and a reliable marker of frailty, may be accelerated by some comorbid conditions including vascular diseases such as congestive heart failure and peripheral arterial diseases [67]. Sarcopenia could worsen the prognosis of many diseases, including AD [68], and a link also exists between sarcopenia-related declines and cognition [69]. Sarcopenia, which produces muscle dysfunction, slow gait velocity and cognitive decline, could share a strong bidirectional relationship, and this suggests the coexistence of both cognitive and motor dysfunctions in older persons to characterize the recently proposed MRC, a syndrome characterized by slow gait and cognitive complaints [70].

\section{Metabolic factors}

Findings from the I-Lan Longitudinal Aging Study (ILAS) identified three distinct subtypes of the phys- 
ical frailty phenotype: non-mobility subtype (weight loss and exhaustion), mobility subtype (slowness and weakness), and physically inactive subtype (low psychical activity) [71]. In the ILAS, compared to robust subjects, people in the non-mobility subtype had poorer bone health and more metabolic serum abnormalities [71]. In particular, in contrast to the muscle catabolic or neurological pathway leading to the mobility subtype, the underlying mechanism of non-mobility subtype may be even more complicated. Interestingly, subjects in the non-mobility subtype had some metabolism-related declines, including poor nutrition status, higher glycated hemoglobin, higher low-density lipoprotein cholesterol, and lower high-density lipoprotein cholesterol serum levels, and they were also the most depressed group overall [71]. Metabolic conditions may be associated with physical frailty independently of sarcopenia [72] and cognitive impairment in older subjects [73]. For example, inappropriate secretion of insulin in response to increased levels of plasma glucose due to insulin resistance results in hyperinsulinemia, which leads to the exposure of cells to high levels of insulin for a long period of time. This situation adversely affects the function and survival of cells, especially neurons [74]. For research purposes, the "metaboliccognitive syndrome" has been proposed as a model of cognitive impairment linked to metabolic syndrome and metabolic disorders in patients with metabolic syndrome plus cognitive impairment of degenerative or vascular origin [75], that could underlie also frailty in older age [76]. In recent years, a plausible mechanism intensively investigated is the accumulation and activation of macrophages in adipose tissue, which may trigger low-grade chronic systemic and neuroinflammation through the release of proinflammatory cytokines [i.e., tumor necrosis factor (TNF), IL-1b, IL-6] [77]. Increased plasma levels of cytokines have been associated with an increased risk of dementia [78]. Dietary saturated fats induce inflammatory responses on microglia, leading to local cytokine production, involving often hypothalamic nuclear factor kappa B activation, which may lead to apoptosis of key neurons involved in body weight control, central regulation of energy balance, glucose homeostasis, and blood pressure [79].

\section{Nutritional factors}

Oxidative stress, low-grade systemic inflammation, neuroinflammation, and altered autophagy, all associated with obesity, metabolic syndrome, and insulin resistance, are proposed mechanisms to explain the influence of nutrition on cognitive health [80], and current epidemiological evidence suggested that diet-related factors may be also associated with late-life cognitive disorders [81, 82]. Older subjects with protein energy undernutrition, a treatable condition, have poorer cognitive performance [83]. Weight loss, reduced caloric intake, and the reduced intake of specific nutrients are associated with detectable changes in body composition and physical function characterizing the transition from independence to disability in older age [84], with weight loss also proposed as a dementia risk factor [85]. Numerous dietary components and supplements with potential antioxidant, anti-inflammatory, and vasodilating actions have been investigated on their effects on cognitive decline. This includes vitamins (e.g., betacarotene, folic acid, vitamin B6 and B12, vitamins C, D, and E), minerals (e.g., zinc and magnesium), n-3 polyunsaturated fatty acids, and other compounds and supplements (e.g., curcumoids, gingko biloba, acetyl-L-carnitine, phytoestrogens, tea and ()-epigallocatechin-3-gallate, resveratrol, garlic, and caffeine) [80]. Adherence to the Mediterranean diet is also associated with slower cognitive decline, reduced risk of $\mathrm{AD}$ and progression from $\mathrm{MCI}$ to $\mathrm{AD}$, and decreased mortality in AD patients $[72,16,86$, 87], confirming the interplay among dietary patterns, frailty, and cognition.

The anorexia of aging, one of the modern geriatric giants, is defined as age-related reduction in appetite and food intake, which occurs even in illness-free adults and in the presence of adequate food supply, resulting from physiological, pathological, and social factors [88]. Loss of appetite may lead to protein-energy malnutrition and weight loss, with numerous poor health outcomes [89], including increased mortality. In the elderly, weight loss is associated with impaired muscle function, falls, decreased bone mass, immune dysfunctions, anemia, pressure ulcers, reduced cognitive functions, poor wound healing, delayed recovery from surgery, functional decline, and increased morbidity and mortality [90]. The decrease in food intake associated with anorexia leads to the frailty syndrome [91]. The etiology of the anorexia of aging is multi-factorial and includes a combination of physiological changes associated with aging (decline in smell and taste, reduced central and peripheral drive to eat, delayed gastric emptying), pathological conditions (depression, dementia, somatic diseases, medications and iatrogenic interventions, 
oral-health status), and social factors (poverty, loneliness) [92].

\section{Hormonal factors}

Once again, sarcopenia may explain the cognitivefrailty link given its association with the development of frailty and cognitive impairment, also through its association with low serum levels of testosterone in men [93]. In fact, reduced testosterone and other androgen hormones may be involved in the development of frailty and cognitive decline. Testosterone may promote hippocampal synaptic plasticity and regulate amyloid deposition [94], while age-related depletion of testosterone may be associated with frailty by reducing muscle mass and strength [95]. Moreover, during aging, a reduction in sex steroids, growth hormone, and vitamin D levels are associated with increased baseline levels of inflammatory proteins [96]. Increased basal cortisol levels have a role in cognitive decline and might be associated with decreased hippocampal volume in patients with Cushing syndrome, depression, and AD [97]. Higher levels of cortisol were associated with worse performance in six cognitive domains (language, processing speed, eye-hand coordination, executive functioning, verbal memory and learning, and visual memory) in adults aged 50 to 70 years, suggesting that dysregulation of the hypothalamic-pituitary adrenal axis (HPA) could be a risk factor for poorer cognitive function in older people [97]. Reduced ghrelin secretion might also contribute to the metabolic changes observed in male patients with AD [98]. Ghrelin has been linked to neuromodulation, neuroprotection, memory, and learning processes due to its expression in different regions of the central nervous system [98].

\section{Inflammatory factors}

Findings from the ILSA suggested that a significant difference in disability rates existed between the MCI and non-MCI groups in frail individuals with high inflammation. Therefore, with inflammation, a potentially reversible cognitive frailty model may have an additional predictive effect on the disability risk than frailty or MCI alone [44]. In frailty, increased markers of inflammation such as CRP or proinflammatory ILs are common [99], with chronic inflammation implicated in the frailty process [100] and also in cognitive impairment and dementia [101]. The possible link among chronic inflammation, physical frailty, and cognition was directly confirmed by some studies [102]. In fact, higher IL-6 and CRP identified one of the subdimensions of the CHS model of physical frailty with elevated predictive validity for mortality [103]. Furthermore, circulating levels of CRP mediated the relationship between muscle strength and poor cognitive function, but only in women [104]. Chronic inflammation is also implicated in a series of possible mediators of the link between physical frailty and cognition such as hormonal dysregulation, oxidative stress, cardiovascular disease, and social isolation [29, 105].

\section{Psychosocial factors}

One psychological factor that may influence the risk of becoming frail in later life is personality, a largely stable set of traits and characteristics that influence behavior, thoughts, and feelings. People who are higher in conscientiousness also have a reduced risk of dying from cardiovascular disease [106], cognitive decline [107], and dementia [108]. On the contrary, people who are higher in neuroticism, the tendency to experience negative emotion, may have an increased risk of cognitive decline [107] and dementia [108]. In a prospective study of people aged 60 to over 90 years, higher levels of neuroticism and lower levels of extraversion and conscientiousness were associated with greater frailty at follow-up around 2 years later [109]. There is evidence that personality may be associated with individual differences in physiological processes that have been hypothesized to underlie the onset of frailty, namely inflammation and the HPA dysregulation [110, 111].

Depression is both a risk factor for and a consequence of frailty. Depression is also known to affect cognitive function [112], suggesting that one mechanism underlying the link between frailty and cognition may be owing to psychological factors such as mood disorders. Moreover, the Health and Retirement Survey showed that participants with vascular depression at baseline were at increased risk of developing frailty [113], suggesting that the interplay between depression and vascular burden may underlie the frailty-cognition link. Finally, depression, especially in the older age group, is often associated to a loss of social networks. In particular, epidemiological [114] and neuropathological [115] evidence suggested that social isolation and loneliness, known contributors to physical frailty [116], may lead to cognitive decline and $\mathrm{AD}$, with limited physical activity further reduced by social isolation [105]. 


\section{DISCUSSION}

Cognitive frailty is a condition recently defined by operationalized criteria describing the contemporary presence of physical frailty and MCI. Two subtypes for this clinical construct have been proposed: potentially reversible cognitive frailty (physical frailty plus MCI) and reversible cognitive frailty (physical frailty plus pre-MCI subjective cognitive decline). In the last two years, several reports have proposed original epidemiological findings strictly using the proposed definition of this novel clinical construct on individuals in older age. These studies suggested a relevant heterogeneity with prevalence estimates ranging from $1.0 \%$ to $22.0 \%$, in particular, from 10.7 to $22 \%$ in clinical-based settings and from 1.0 to $4.4 \%$ in population-based settings. Cross-sectional and longitudinal population-based studies suggested that different cognitive frailty models may be associated with increased risk of functional disability, worsened quality of life, hospitalization, and all-cause mortality. Some large longitudinal population-based studies showed that different cognitive frailty models may increase the risk of incidence of dementia, $\mathrm{VaD}$, and neurocognitive disorders.

\section{Preventive strategies for cognitive frailty}

In older subjects, at community level, primary preventive intervention to delay onset of frailty includes the promotion of physical activities, exercise and a healthy diet, the cessation of smoking, engaging in an active and socially integrated lifestyle, the maintenance of a proper body weight, and metabolic and vascular risk control, including dyslipidemia, diabetes, and blood pressure [117]. Physical frailty and cognitive frailty are two phenotypes of frailty that are becoming possible secondary prevention targets in early/asymptomatic dementia stage [36]. Cognitive frailty, a clinical construct reassembling cognitive impairment associated to its possible physical causes, has a potential for reversibility. Of course, at this stage, the prevention of cognitive frailty progression towards overt dementia is only a striking hypothesis. However, fulfilling the compression of morbidity hypothesis originally proposed by Fries, in which the burden of lifetime disease may be compressed into a shorter period before the time of death, if the age of onset of the first chronic infirmity can be postponed [118], the prevention of cognitive frailty progression may increase survival also in the very old with cognitive impairment deriving from physical causes or at least their quality of life and functional independence [119]. For different models of cognitive frailty, physical frailty should precede the onset of cognitive impairment [120], thus, intervention programs targeted to improve frailty may prevent also latelife cognitive disorders. An understanding of best clinical management strategies targeting frailty in multiple settings is evolving. Convincing evidence from high-quality studies is lacking [121, 122], however, new systematic reviews are underway [123, 124]. Physical activity and nutrition are the overarching interventions for prevention and management of frailty $[80,125,126]$. Systematic reviews supported the value of exercise interventions in decreasing falls and improving gait ability $[125,126]$, while there was only preliminary evidence coming from RCTs that nutrition could postpone frailty in older age [127]. A healthy dietary pattern, namely the Mediterranean diet, has shown to positively affect both physical and cognitive frailty $[29,80,128]$. The Finnish Geriatric Intervention Study to Prevent Cognitive Impairment and Disability (FINGER) study showed that a multidomain intervention combining Mediterranean diet, exercise, and brain stimulation slowed cognitive loss in older adults [129]. Nutrition itself may be considered a multidomain intervention due to its ability to deliver benefit at biological, clinical, and social levels [80]. A very recent systematic review showed that multidomain interventions tended to be more effective than monodomain interventions on frailty status or score, muscle mass and strength, and physical functioning, while findings were inconclusive for cognitive, functional, and social outcomes [130]. Physical exercise seems to play an essential role in the multidomain intervention, whereby additional interventions can lead to further improvement (i.e., nutritional intervention) [130]. At this stage of clinical development of the construct of cognitive frailty, secondary preventive strategies for cognitive impairment and physical frailty may be suggested. For older subjects with cognitive frailty, particularly reversible cognitive frailty, secondary prevention is required, with a CGA determining the cause of cognitive frailty and an evidence-based and individualized multidomain interventions similar to that of the FINGER [129]. Other measures, such as drug treatment for chronic diseases, fall prevention, and exercise and nutrition support, which target physical, nutritional, cognitive, and psychological domains, may delay the progression to overt dementia and secondary occurrence of adverse health-related outcomes, such as disability, hospitalization, and mortality [49, 117]. 
Although evidence on interventions in cognitive frail subjects is limited, a small number of studies point to the cognitive benefits of physical activity and nutrition. In fact, physical activity protected against both sarcopenia and cognitive decline in experimental training trials and in observational studies [131]. Furthermore, findings from recent preventive RCTs suggested that physical exercise training in combination with protein supplementation [132] or alone [133] improved also cognitive outcomes in frail and pre-frail states, opening new viable routes for the prevention of cognitive and functional decline in these patients.

\section{Controversies and future directions}

A recent expert consensus panel of the IAGG and its Global Aging Research Network (GARN) agreed that persons with cognitive decline should be screened for physical frailty and vice versa [128], although the IAGG-GARN panelists agreed that more studies on the interaction of the two entities and their pathophysiology are needed [128]. In fact, also open and unresolved issues exist in the field and the concept of cognitive frailty has still significant limitations for its broad implementation in clinical practice. A robust operational definition of its individual components (i.e., physical frailty and cognitive impairment) and characterization of the clinical and biological mediators are still lacking [128, 134, 135], although, in the last two years, a growing body of epidemiological evidence suggested preliminary clinical validation for this clinical construct [43, 44, 49-54]. No universal criteria or consensus operational definition has been reached for frailty, and therefore also for its phenotypes, including cognitive frailty. However, the current working definitions of cognitive frailty $[20,34,38]$ may provide a valuable starting point for the development of a coherent and largely accepted operational definition. Notwithstanding, we need different operational definitions for its individual components. While the physical factors of cognitive frailty were diagnosed with the physical frailty model operationalized with the CHS criteria, the cognitive pattern of this clinical construct was not clearly characterized. In the epidemiological section of the present review, we did not include some studies estimating the prevalence of cognitive frailty and using frailty indexes based deficit accumulation model to operationalize frailty [136, 137]. Of course, frailty indexes were investigated in studies associating frailty to late-life cognitive disorders [39], in particular, the nontraditional risk factors index (Frailty Index-NTRF) that was developed using a series of 19 deficits not known to predict dementia and AD [139]. Furthermore, very recently, findings from the Toledo Study for Healthy Aging Cognitive suggested that cognitive performance was worse with a worse degree of frailty, independently of the model used (physical frailty, frailty indexes, or the Frailty Trait Scale, a new muldimensional measure of frailty) [139]. However, the studies published so far using the IANA/IAGG criteria adopted the definition of physical frailty almost exclusively operationalized by considering the CHS criteria [7]. Furthermore, given the potential for reversibility of the cognitive frailty construct, physical frailty identifies a primary or pre-clinical frailty state [15], i.e., a potential target for prevention. On the contrary, frailty indexes identify secondary or clinical frailty [15], associated with known comorbidities and/or disability, a condition that can be unlikely reversed. However, cognitive frailty is not an uncontroversial term. In fact, a motor signature that preceded cognitive decline and which has been labeled as the Motoric Cognitive Risk syndrome, the combination of slow gait and objective cognitive impairment, further casted doubt on the empirical basis of the cognitive frailty syndrome [55]. For the cognitive impairment component, although the relevant heterogeneity observed in recent systematic reviews [41, 42], epidemiological findings suggested that the ability of different cognitive frailty models in predicting cognitive-related outcomes may arise from the different ways in which cognitive impairment may be operationalized [44, 54]. In fact, while a potentially reversible cognitive frailty model (physical frailty plus MCI) had no predictive role for the development of incident dementia compared with physical frailty or MCI alone [44], a model of reversible cognitive frailty (physical frailty plus pre-MCI SCD) was a short- and long-term predictor of overall dementia, particularly $\mathrm{VaD}$ [54], suggesting that subjective cognitive disturbances may be central for the definition of cognitive impairment in cognitive frailty. The early detection of cognitive disturbances at a subjective level may be a promising focus for the development of preventive and therapeutic interventions. Finally, none of the available studies on cognitive frailty explicitly addressed the relationship between physical frailty and cognitive impairment within the cognitive frailty construct [135], identifying conditions characterized by the cooccurrence of physical and cognitive decline, without clarifying their relationship. A causal, or at least, 
temporal criterion could be crucial to increase the possibility of detecting cognitive disturbances related to physical causes, so representing a single complex phenotype, as suggested by the cognitive frailty construct [39]. Alternatively, physical frailty and cognitive impairment could be two different consequences of a common underlying mechanism (i.e., vascular diseases or neurodegeneration) or representing two separate and coexisting conditions occurring in older age. In conclusion, reversible cognitive and functional damages as defined in these models of cognitive frailty could be an optimal target for a secondary prevention of cognitive and functional impairment also for early/asymptomatic dementia stage. The operationalization of clinical constructs based on cognitive impairment related to physical causes (physical frailty, motor function decline, or other physical factors) appears to be interesting for dementia secondary prevention given the increased risk for progression to dementia of these clinical entities. In the near future, the present consensual criteria for cognitive frailty should be redefined, with the use of different operational definitions for frailty and cognitive impairment, and useful clinical, biological, and imaging markers to develop a better understanding of the bidirectional relationship of these conditions, preventing late-life cognitive disorders with intervention programs targeted to improve frailty.

\section{DISCLOSURE STATEMENT}

Authors' disclosures available online (https:// www.j-alz.com/manuscript-disclosures/17-0963r1).

\section{REFERENCES}

[1] Morley JE (2004) A brief history of geriatrics. J Gerontol A Biol Sci Med Sci 59, 1132-1152.

[2] Morley JE (2017) The new geriatric giants. Clin Geriatr Med 33, xi-xii.

[3] Vaupel JW, Manton KG, Stallard E (1979) The impact of heterogeneity in individual frailty on the dynamics of mortality. Demography 16, 439-454.

[4] Morley JE, Vellas B, Abellan van Kan G, Anker SD, Bauer JM, Bernabei R, Cesari M, Chumlea WC, Doehner W, Evans J, Fried LP, Guralnik JM, Katz PR, Malmstrom TK, McCarter RJ, Gutierrez Robledo LM, Rockwood K, von Haehling S, Vandewoude MF, Walston J (2013) Frailty consensus: A call to action. J Am Med Dir Assoc 14, 392397.

[5] Shamliyan T, Talley KM, Ramakrishnan R, Kane RL (2013) Association of frailty with survival: A systematic literature review. Ageing Res Rev 12, 719-736.

[6] Dent E, Lien C, Lim WS, Wong WC, Wong CH, Ng TP, Woo J, Dong B, de la Vega S, Hua Poi PJ, Kamaruzzaman
SBB, Won C, Chen LK, Rockwood K, Arai H, RodriguezMañas L, Cao L, Cesari M, Chan P, Leung E, Landi F, Fried LP, Morley JE, Vellas B, Flicker L (2017) The Asia-Pacific clinical practice guidelines for the management of frailty. J Am Med Dir Assoc 18, 564-575.

[7] Fried LP, Tangen CM, Walston J, Newman AB, Hirsch C, Gottdiener J, Seeman T, Tracy R, Kop WJ, Burke G, McBurnie MA, Cardiovascular Health Study Collaborative Research Group (2001) Frailty in older adults: Evidence for a phenotype. J Gerontol A Biol Sci Med Sci 56, M146-56.

[8] Mitnitski AB, Mogilner AJ, Rockwood K (2001) Accumulation of deficits as a proxy measure of aging. ScientificWorldJournal 1, 323-336.

[9] Rockwood K, Song X, MacKnight C, Bergman H, Hogan DB, McDowell I, Mitnitski (2005) A global clinical measure of fitness and frailty in elderly people. CMAJ 173, 489-495.

[10] Pilotto A, Cella A, Pilotto A, Daragjati J, Veronese N, Musacchio C, Mello AM, Logroscino G, Padovani A, Prete C, Panza F (2017) Three decades of comprehensive geriatric assessment: Evidence coming from different healthcare settings and specific clinical conditions. $J \mathrm{Am}$ Med Dir Assoc 18, 192.e1-192.e11.

[11] Gobbens RJ, Luijkx KG, Wijnen-Sponselee MT, Schols JM (2010) In search of an integral conceptual definition of frailty: Opinions of experts. J Am Med Dir Assoc 11, 338-343.

[12] Gobbens RJ, van Assen MA, Luijkx KG, Schols JM (2012) Testing an integral conceptual model of frailty. J Adv Nurs 68, 2047-2060.

[13] Drachman DA (2006) Aging of the brain, entropy, and Alzheimer disease. Neurology 67, 1340-1352.

[14] Boockvar KS, Meier DE (2006) Palliative care for frail older adults. JAMA 296, 2245-2253.

[15] Strandberg TE, Pitkälä KH (2006) Frailty in elderly people. Lancet 369, 1328-1329.

[16] Kelaiditi E, Abellan van Kan G, Cesari M (2014) Frailty: Role of nutrition and exercise. Curr Opin Clin Nutr Metab Care 17, 32-39.

[17] Mezuk B, Edwards L, Lohman M, Choi M, Lapane K (2012) Depression and frailty in later life: A synthetic review. Int J Geriatr Psychiatry 27, 879-892.

[18] Panza F, Solfrizzi V, Frisardi V, Maggi S, Sancarlo D, Adante F, D'Onofrio G, Seripa D, Pilotto A (2011) Different models of frailty in predementia and dementia syndromes. J Nutr Health Aging 15, 711-719.

[19] Ruan Q, Yu Z, Chen M, Bao Z, Li J, He W (2015) Cognitive frailty, a novel target for the prevention of elderly dependency. Ageing Res Rev 20, 1-10.

[20] Bunt S, Steverink N, Olthof J, van der Schans CP, Hobbelen JSM (2017) Social frailty in older adults: A scoping review. Eur J Ageing 14, 323-334.

[21] Fitten LJ (2015) Psychological frailty in the aging patient. Nestle Nutr Inst Workshop Ser 83, 45-53.

[22] Brown PJ, Rutherford BR, Yaffe K, Tandler JM, Ray JL, Pott E, Chung S, Roose SP (2016) The depressed frail phenotype: The clinical manifestation of increased biological aging. Am J Geriatr Psychiatry 24, 1084-1094.

[23] Garre-Olmo J, Calvó-Perxas L, López-Pousa S, de Gracia Blanco M, Vilalta-Franch J (2013) Prevalence of frailty phenotypes and risk of mortality in a community-dwelling elderly cohort. Age Ageing 42, 46-51.

[24] Tsutsumimoto K, Doi T, Makizako H, Hotta R, Nakakubo S, Makino K, Suzuki T, Shimada H (2017) Association 
of social frailty with both cognitive and physical deficits among older people. J Am Med Dir Assoc 18, 603-607.

[25] Teo N, Gao Q, Nyunt MSZ, Wee SL, Ng TP (2017) Social frailty and functional disability: Findings from the Singapore Longitudinal Ageing Studies. J Am Med Dir Assoc 18, 637.e13-637.e19.

[26] Gill TM, Allore HG, Hardy SE, Guo Z (2006) The dynamic nature of mobility disability in older persons. J Am Geriatr Soc 54, 248-254.

[27] Ament BHL, de Vugt ME, Verhey FRJ, Kempen GIJM (2014) Are physically frail older persons more at risk of adverse outcomes if they also suffer from cognitive, social, and psychological frailty? Eur J Ageing 11, 213-219.

[28] Canevelli M, Troili F, Bruno G (2014) Reasoning about frailty in neurology: Neurobiological correlates and clinical perspectives. J Frailty Aging 3, 18-20.

[29] Robertson DA, Savva GM, Kenny RA (2013) Frailty and cognitive impairment-a review of the evidence and causal mechanisms. Ageing Res Rev 12, 840-851.

[30] Malmstrom TK, Morley JE (2013) Frailty and cognition: Linking two common syndromes in older persons. J Nutr Health Aging 17, 723-725.

[31] Godin J, Armstrong JJ, Rockwood K, Andrew MK (2017) Dynamics of frailty and cognition after age 50: Why it matters that cognitive decline is mostly seen in old age. J Alzheimers Dis 58, 231-242.

[32] Paganini-Hill A, Clark LJ, Henderson VW, Birge SJ (2001) Clock drawing: Analysis in a retirement community. J Am Geriatr Soc 49, 941-947.

[33] Chouliara Z1, Kearney N, Stott D, Molassiotis A, Miller M (2004) Perceptions of older people with cancer of information, decision making and treatment: A systematic review of selected literature. Ann Oncol 15, 1596-1602.

[34] Panza F, D'Introno A, Colacicco AM, Capurso C, Parigi AD, Capurso SA, Caselli RJ, Pilotto A, Scafato E, Capurso A, Solfrizzi V (2006) Cognitive frailty: Predementia syndrome and vascular risk factors. Neurobiol Aging 27, 933-940.

[35] Kelaiditi E, Cesari M, Canevelli M, van Kan GA, Ousset PJ, Gillette-Guyonnet S, Ritz P, Duveau F, Soto ME, Provencher V, Nourhashemi F, Salvá A, Robert P, Andrieu $\mathrm{S}$, Rolland Y, Touchon J, Fitten JL, Vellas B, IANA/IAGG (2013) Cognitive frailty: Rational and definition from an (I.A.N.A./I.A.G.G.) international consensus group. J Nutr Health Aging 17, 726-734.

[36] Panza F, Lozupone M, Solfrizzi V, Stallone R, Bellomo A, Greco A, Daniele A, Seripa D, Logroscino G (2017) Cognitive frailty: A potential target for secondary prevention of dementia. Expert Opin Drug Metab Toxicol 13, 1023-1027.

[37] Panza F, Solfrizzi V, Barulli MR, Santamato A, Seripa D, Pilotto A, Logroscino G (2015) Cognitive frailty: A systematic review of epidemiological and neurobiological evidence of an age-related clinical condition. Rejuvenation Res 18, 389-412.

[38] Kojima G, Taniguchi Y, Iliffe S, Walters K (2016) Frailty as a predictor of Alzheimer disease, vascular dementia, and all dementia among community-dwelling older people: A systematic review and meta-analysis. J Am Med Dir Assoc 17, 881-888.

[39] Panza F, Seripa D, Solfrizzi V, Tortelli R, Greco A, Pilotto A, Logroscino G (2015) Targeting cognitive frailty: Clinical and neurobiological roadmap for a single complex phenotype. J Alzheimers Dis 47, 793-813.
[40] Jessen F, Amariglio RE, van Boxtel M, Breteler M, Ceccaldi M, Chételat G, Dubois B, Dufouil C, Ellis KA, van der Flier WM, Glodzik L, van Harten AC, de Leon MJ, McHugh P, Mielke MM, Molinuevo JL, Mosconi L, Osorio RS, Perrotin A, Petersen RC, Rabin LA, Rami L, Reisberg B, Rentz DM, Sachdev PS, de la Sayette V, Saykin AJ, Scheltens P, Shulman MB, Slavin MJ, Sperling RA, Stewart R, Uspenskaya O, Vellas B, Visser PJ, Wagner $\mathrm{M}$, Subjective Cognitive Decline Initiative (SCD-I) Working Group (2014) A conceptual framework for research on subjective cognitive decline in preclinical Alzheimer's disease. Alzheimers Dement 10, 844-852.

[41] Xie B, Larson JL, Gonzalez R, Pressler SJ, Lustig C, Arslanian-Engoren C (2017) Components and indicators of frailty measures: A literature review. J Frailty Aging $\mathbf{6}$, 76-82.

[42] Sargent L, Brown R (2017) Assessing the current state of cognitive frailty: Measurement properties. J Nutr Health Aging 21, 152-160.

[43] Delrieu J, Andrieu S, Pahor M, Cantet C, Cesari M, Ousset PJ, Voisin T, Fougère B, Gillette $S$, Carrie I, Vellas B (2016) Neuropsychological profile of "cognitive frailty" subjects in MAPT study. J Prev Alzheimers Dis 3, 151-159.

[44] Solfrizzi V, Scafato E, Lozupone M, Seripa D, Giannini M, Sardone R, Bonfiglio C, Abbrescia DI, Galluzzo L, Gandin C, Baldereschi M, Di Carlo A, Inzitari D, Daniele A, Sabbá C, Logroscino G, Panza F, Italian Longitudinal Study on Aging Working Group (2017) Additive role of a potentially reversible cognitive frailty model and inflammatory state on the risk of disability. The Italian Longitudinal Study on Aging. Am J Geriatr Psychiatry 25, 1236-1248.

[45] Sperling RA Aisen PS, Beckett LA, Bennett DA, Craft S, Fagan AM, Iwatsubo T, Jack CR Jr, Kaye J, Montine TJ, Park DC, Reiman EM, Rowe CC, Siemers E, Stern Y, Yaffe K, Carrillo MC, Thies B, Morrison-Bogorad M, Wagster MV, Phelps CH (2011) Toward defining the preclinical stages of Alzheimer's disease: Recommendations from the National Institute on Aging-Alzheimer's Association workgroups on diagnostic guidelines for Alzheimer's disease. Alzheimers Dement 7, 280-292.

[46] Albert MS, DeKosky ST, Dickson D, Dubois B, Feldman HH, Fox NC, Gamst A, Holtzman DM, Jagust WJ, Petersen RC, Snyder PJ, Carrillo MC, Thies B, Phelps CH (2011) The diagnosis of mild cognitive impairment due to Alzheimer's disease: Recommendations from the National Institute on Aging-Alzheimer's Association workgroups on diagnostic guidelines for Alzheimer's disease. Alzheimers Dement 7, 270-279.

[47] Genin E, Hannequin D, Wallon D, Sleegers K, Hiltunen M, Combarros O, Bullido MJ, Engelborghs S, De Deyn P, Berr C, Pasquier F, Dubois B, Tognoni G, Fiévet N, Brouwers N, Bettens K, Arosio B, Coto E, Del Zompo M, Mateo I, Epelbaum J, Frank-Garcia A, Helisalmi S, Porcellini E, Pilotto A, Forti P, Ferri R, Scarpini E, Siciliano G, Solfrizzi V, Sorbi S, Spalletta G, Valdivieso F, Vepsäläinen S, Alvarez V, Bosco P, Mancuso M, Panza F, Nacmias B, Bossú P, Hanon O, Piccardi P, Annoni G, Seripa D, Galimberti D, Licastro F, Soininen H, Dartigues JF, Kamboh MI, Van Broeckhoven C, Lambert JC, Amouyel P, Campion D (2011) APOE and Alzheimer disease: A major gene with semi-dominant inheritance. Mol Psychiatry 16, 903-907.

[48] Ruan Q, D’Onofrio G, Sancarlo D, Greco A, Lozupone M, Seripa D, Panza F, Yu Z (2017) Emerging biomarkers and screening for cognitive frailty. Aging Clin Exp Res 29, 1075-1086. 
[49] Shimada H, Makizako H, Lee S, Doi T, Lee S, Tsutsumimoto K, Harada K, Hotta R, Bae S, Nakakubo S, Harada K, Suzuki T (2016) Impact of cognitive frailty on daily activities in older persons. J Nutr Health Aging 20, 729735.

[50] Roppolo M, Mulasso A, Rabaglietti E (2017) Cognitive frailty in Italian community dwelling older adults: Prevalence rate and its association with disability. J Nutr Health Aging 21, 631-636.

[51] Feng L, Zin Nyunt MS, Gao Q, Feng L, Yap KB, Ng TP (2017) Cognitive frailty and adverse health outcomes: Findings from the Singapore Longitudinal Ageing Studies (SLAS). J Am Med Dir Assoc 18, 252-258.

[52] Montero-Odasso MM, Barnes B, Speechley M, Muir Hunter SW, Doherty TJ, Duque G, Gopaul K, Sposato LA, Casas-Herrero A, Borrie MJ, Camicioli R, Wells JL (2016) Disentangling cognitive frailty: Results from the Gait and Brain Study. J Gerontol A Biol Sci Med Sci 71, 1476-1482.

[53] Feng L, Nyunt MSZ, Gao Q, Feng L, Lee TS, Tsoi T, Chong MS, Lim WS, Collinson S, Yap P, Yap KB, Ng TP (2017) Physical frailty, cognitive impairment, and the risk of neurocognitive disorder in the Singapore Longitudinal Ageing Studies. J Gerontol A Biol Sci Med Sci 72, 369-375.

[54] Solfrizzi V, Scafato E, Seripa D, Lozupone M, Imbimbo BP, D’Amato A, Tortelli R, Schilardi A, Galluzzo L, Gandin C, Baldereschi M, Di Carlo A, Inzitari D, Daniele A, Sabbá C, Logroscino G, Panza F; Italian Longitudinal Study on Aging Working Group (2017) Reversible cognitive frailty, dementia, and all-cause mortality. The Italian Longitudinal Study on Aging. J Am Med Dir Assoc 18, 89.e1-89.e8.

[55] Kueper JK, Speechley M, Lingum NR, Montero-Odasso M (2017) Motor function and incident dementia: A systematic review and meta-analysis. Age Ageing 46, 729738.

[56] Canevelli M, Cesari M, Abellan van Kan G (2015) Frailty and cognitive decline: How do they relate? Curr Opin Clin Nutr Metab Care 18, 43-50.

[57] Searle SD, Rockwood K (2015) Frailty and the risk of cognitive impairment. Alzheimers Res Ther 7, 54.

[58] Halil M, Kizilarslanoglu MC, Kuyumcu ME, Yesil Y, Cruz Jentoft AJ (2015) Cognitive aspects of frailty: Mechanisms behind the link between frailty and cognitive impairment. J Nutr Health Aging 19, 276-283.

[59] Clegg A, Young J, Iliffe S, Rikkert MO, Rockwood K (2013) Frailty in elderly people. Lancet 381, 752-762. Erratum in: Lancet (2013) 382, 1328.

[60] Avila-Funes JA, Carcaillon L, Helmer C, Carrière I, Ritchie K, Rouaud O, Tzourio C, Dartigues JF, Amieva H. (2012) Is frailty a prodromal stage of vascular dementia? Results from the Three-City Study. J Am Geriatr Soc 60, 1708-1712.

[61] Solfrizzi V, Scafato E, Frisardi V, Seripa D, Logroscino G, Maggi S, Imbimbo BP, Galluzzo L, Baldereschi M, Gandin C, Di Carlo A, Inzitari D, Crepaldi G, Pilotto A, Panza F; Italian Longitudinal Study on AgingWorking Group (2013) Frailty syndrome and the risk of vascular dementia: The Italian Longitudinal Study on Aging. Alzheimers Dement 9, 113-122.

[62] Newman AB, Gottdiener JS, Mcburnie MA, Hirsch CH, Kop WJ, Tracy R, Walston JD, Fried LP, Cardiovascular Health Study Research, Group (2001) Associations of subclinical cardiovascular disease with frailty. J Gerontol A Biol Sci Med Sci 56, M158-M166.
[63] Morley JE (2015) White matter lesions (leukoaraiosis): A major cause of falls. J Am Med Dir Assoc 16, 441-443.

[64] Nadruz W Jr, Kitzman D, Windham BG, KucharskaNewton A, Butler K, Palta P, Griswold ME, Wagenknecht LE, Heiss G, Solomon SD, Skali H, Shah AM (2017) Cardiovascular dysfunction and frailty among older adults in the community: The ARIC Study. J Gerontol A Biol Sci Med Sci 72, 958-964.

[65] Cruz-Jentoft AJ, Baeyens JP, Bauer JM, Boirie Y, Cederholm T, Landi F, Martin FC, Michel JP, Rolland Y, Schneider SM, Topinková E, Vandewoude M, Zamboni M, European Working Group on Sarcopenia in Older People (2010) Sarcopenia: European consensus on definition and diagnosis: Report of the European Working Group on Sarcopenia in Older People. Age Ageing 39, 412-423.

[66] Dam TT, Peters KW, Fragala M, Cawthon PM, Harris TB, McLean R, Shardell M, Alley DE, Kenny A, Ferrucci L, Guralnik J, Kiel DP, Kritchevsky S, Vassileva MT, Studenski S (2014) An evidence-based comparison of operational criteria for the presence of sarcopenia. J Gerontol A Biol Sci Med Sci 69, 584-590.

[67] Buford TW, Anton SD, Judge AR, Marzetti E, Wohlgemuth SE, Carter CS, Leeuwenburgh C, Pahor M, Manini TM (2010) Models of accelerated sarcopenia: Critical pieces for solving the puzzle of age-related muscle atrophy. Ageing Res Rev 9, 369-383.

[68] Kuljis RO, Salkovic-Petrisic M (2011) Dementia, diabetes, Alzheimer's disease, and insulin resistance in the brain: Progress, dilemmas, new opportunities, and a hypothesis to tackle intersecting epidemics. J Alzheimers Dis 25, 29-41.

[69] Nourhashemi F, Andrieu S, Gillette-Guyonnet S, Reynish E, Albarede JL, Grandjean H, Vellas B (2002) Is there a relationship between fat-free soft tissue mass and low cognitive function? results from a study of 7,105 women. $J$ Am Geriatr Soc 50, 1796-1801.

[70] Lauretani F, Meschi T, Ticinesi A, Maggio M (2017) "Brain-muscle loop" in the fragility of older persons: From pathophysiology to new organizing models. Aging Clin Exp Res 29, 1305-1311.

[71] Liu LK, Guo CY, Lee WJ, Chen LY, Hwang AC, Lin MH, Peng LN, Chen LK, Liang KY (2017) Subtypes of physical frailty: Latent class analysis and associations with clinical characteristics and outcomes. Sci Rep 7, 46417.

[72] Panza F, Solfrizzi V, Logroscino G, Maggi S, Santamato A, Seripa D, Pilotto A (2012) Current epidemiological approaches to the metabolic-cognitive syndrome. J Alzheimers Dis 30(Suppl 2), S31-S75.

[73] Karakelides H, Nair KS (2005) Sarcopenia of aging and its metabolic impact. Curr Top Dev Biol 68, 123-148.

[74] Neumann KF, Rojo L, Navarrete LP, Farias G, Reyes P, Maccioni RB (2008) Insulin resistance and Alzheimer's disease: Molecular links \& clinical implications. Curr Alzheimer Res 5, 438-447.

[75] Frisardi V, Solfrizzi V, Seripa D, Capurso C, Santamato A, Sancarlo D, Vendemiale G, Pilotto A, Panza F (2010) Metabolic-cognitive syndrome: A cross-talk between metabolic syndrome and Alzheimer's disease. Ageing Res Rev 9, 399-417.

[76] Semprini R, Ragonese M, Poggi M, Franze A, Martorana A (2013) Ageing as a Trait de Union between diabetes and dementia for frailty. CNS Neurol Disord Drug Targets 12, 520-524.

[77] Grant RW, Dixit VD (2015) Adipose tissue as an immunological organ. Obesity (Silver Spring) 23, 512-518. 
[78] Heneka MT, Carson MJ, El Khoury J, Landreth GE, Brosseron F, Feinstein DL, Jacobs AH, Wyss-Coray T, Vitorica J, Ransohoff RM, Herrup K, Frautschy SA, Finsen B, Brown GC, Verkhratsky A, Yamanaka K, Koistinaho J, Latz E, Halle A, Petzold GC, Town T, Morgan D, Shinohara ML, Perry VH, Holmes C, Bazan NG, Brooks DJ, Hunot S, Joseph B, Deigendesch N, Garaschuk O, Boddeke E, Dinarello CA, Breitner JC, Cole GM, Golenbock DT, Kummer MP (2015) Neuroinflammation in Alzheimer's disease. Lancet Neurol 14, 388-405.

[79] Velloso LA, Folli F, Saad MJ (2015) TLR4 at the crossroads of nutrients, gut microbiota, and metabolic inflammation. Endocr Rev 36, 245-271.

[80] Dominguez LJ, Barbagallo M (2017) The relevance of nutrition for the concept of cognitive frailty. Curr Opin Clin Nutr Metab Care 20, 61-68.

[81] Luchsinger JA, Noble JM, Scarmeas N (2007) Diet and Alzheimer's disease. Curr Neurol Neurosci Rep 7, 366372.

[82] Lourida I, Soni M, Thompson-Coon J, Purandare N, Lang IA, Ukoumunne OC, Llewellyn DJ (2013) Mediterranean diet, cognitive function, and dementia: A systematic review. Epidemiology 24, 479-489.

[83] Cesari M (2013) Perspective: Protein supplementation against sarcopenia and frailty - future perspectives from novel data. J Am Med Dir Assoc 14, 62-63.

[84] Morley JE (2014) Cognition and nutrition. Curr Opin Clin Nutr Metab Care 17, 1-4.

[85] Knopman DS, Edland SD, Cha RH, Petersen RC, Rocca WA (2007) Incident dementia in women is preceded by weight loss by at least a decade. Neurology 69, 739-746.

[86] Tangney CC (2014) DASH and Mediterranean-type dietary patterns to maintain cognitive health. Curr Nutr Rep 3, 51-61.

[87] Solfrizzi V, Panza F (2014) Mediterranean diet and cognitive decline. A lesson from the whole-diet approach: What challenges lie ahead? J Alzheimers Dis 39, 283-286.

[88] Morley JE, Silver AJ (1988) Anorexia in the elderly. Neurobiol Aging 9, 9-16.

[89] Soenen S, Chapman IM (2013) Body weight, anorexia, and undernutrition in older people. J Am Med Dir Assoc 14, 642-648.

[90] MacIntosh C, Morley JE, Chapman IM (2000) The anorexia of aging. Nutrition 16, 983-995.

[91] Martone AM, Onder G, Vetrano DL, Ortolani E, Tosato M, Marzetti E, Landi F (2013) Anorexia of aging: A modifiable risk factor for frailty. Nutrients 5, 4126-4133.

[92] Wysokiński A, Sobów T, Kłoszewska I, Kostka T (2015) Mechanisms of the anorexia of aging-a review. Age (Dordr) 37, 9821.

[93] Auyeung TW, Lee JS, Kwok T, Leung J, Ohlsson C, Vandenput L, Leung PC, Woo J (2011) Testosterone but not estradiol level is positively related to muscle strength and physical performance independent of muscle mass: A cross-sectional study in 1489 older men. Eur J Endocrinol 164, 811-817.

[94] Maggio M, Dall'Aglio E, Lauretani F, Cattabiani C, CeresiniG, Caffarra P, Valenti G, Volpi R, Vignali A, Schiavi G, Ceda GP (2012) The hormonal pathway to cognitive impairment in older men. J Nutr Health Aging 16, 40-54.

[95] Morley JE, Malmstrom TK (2013) Frailty, sarcopenia, and hormones. Endocrinol Metab Clin North Am 42, 391-405.

[96] Hunt KJ, Walsh BM, Voegeli D, Roberts HC (2010) Inflammation in aging part 2: Implications for the health of older people and recommendations for nursing practice. Biol Res Nurs 11, 253-260.

[97] Lee BK, Glass TA, McAtee MJ, Wand GS, BandeenRoche K, Bolla KI, Schwartz BS (2007) Associations of salivary cortisol with cognitive function in the Baltimore memory study. Arch Gen Psychiatry 64, 810-818.

[98] Gahete MD, Cordoba-Chacon J, Kineman RD, Luque RM, Castano JP (2011) Role of ghrelin system in neuroprotection and cognitive functions: Implications in Alzheimer's disease. Peptides 32, 2225-2228.

[99] Puts MT, Visser M, Twisk JW, Deeg DJ, Lips P (2005) Endocrine and inflammatory markers as predictors of frailty. Clin Endocrinol 63, 403-411.

[100] Weaver JD, Huang MH, Albert M, Harris T, Rowe JW, Seeman TE (2002) Interleukin-6 and risk of cognitive decline: MacArthur studies of successful aging. Neurology 59, 371-378.

[101] Ma SL, Tang NL, Lam LC, Chiu HF (2005) The association between promoter polymorphism of the interleukin-10 gene and Alzheimer's disease. Neurobiol Aging 26, 1005-1010.

[102] Sarkisian CA, Gruenewald TL, John Boscardin W, Seeman TE (2008) Preliminary evidence for subdimensions of geriatric frailty: The MacArthur study of successful aging. J Am Geriatr Soc 56, 2292-2297.

[103] Canon ME, Crimmins EM (2011) Sex differences in the association between muscle quality, inflammatory markers, and cognitive decline. J Nutr Health Aging 15, 695-698.

[104] Mocchegiani E, Corsonello A, Lattanzio F (2010) Frailty, ageing and inflammation: Reality and perspectives. Biogerontology 11, 523-525.

[105] Hawkley LC, Hughes ME, Waite LJ, Masi CM, Thisted RA, Cacioppo JT (2008) From social structural factors to perceptions of relationship quality and loneliness: The Chicago health, aging, and social relations study. J Gerontol B Psychol Sci Soc Sci 63, S375-S384.

[106] Jokela M, Pulkki-Raback L, Elovainio M, Kivimaki M (2014) Personality traits as risk factors for stroke and coronary heart disease mortality: Pooled analysis of three cohort studies. J Behav Med 37, 881-889.

[107] Luchetti M, Terracciano A, Stephan Y, Sutin AR (2015) Personality and cognitive decline in older adults: Data from a longitudinal sample and meta-analysis. J Gerontol B Psychol Sci Soc Sci 71, 591-601.

[108] Low LF, Harrison F, Lackersteen SM (2013) Does personality affect risk for dementia? A systematic review and meta-analysis. Am J Geriatr Psychiatry 21, 713-728.

[109] Gale CR, Mõttus R, Deary IJ, Cooper C, Sayer AA (2017) Personality and risk of frailty: The English Longitudinal Study of Ageing. Ann Behav Med 51, 128-136.

[110] Sutin AR, Terracciano A, Deiana B, Naitza S, Ferrucci L, Uda M, Schlessinger D, Costa PT Jr (2010) High neuroticism and low conscientiousness are associated with interleukin-6. Psychol Med 40, 1485-1493.

[111] Mottus R, Luciano M, Starr JM, Pollard MC, Deary IJ (2013) Personality traits and inflammation in men and women in their early 70s: The Lothian Birth Cohort 1936 study of healthy aging. Psychosom Med 75, 11-19.

[112] Lee RSC, Hermens DF, Porter MA, Redoblado-Hodge MA (2012) A meta-analysis of cognitive deficits in firstepisode major depressive disorder. J Affect Disord 140, 113-124. 
[113] Paulson D, Lichtenberg PA (2012) Vascular depression: An early warning sign of frailty. Aging Ment Health 17, 85-93.

[114] Fratiglioni L, Wang HX, Ericsson K, Maytan M, Winblad B (2000) Influence of social network on occurrence of dementia: A community-based longitudinal study. Lancet 355, 1315-1319.

[115] Wilson RS, Krueger KR, Arnold SE, Schneider JA, Kelly JF, Barnes LL, Tang Y, Bennett DA (2007) Loneliness and risk of Alzheimer disease. Arch Gen Psychiatry 64, 234-240.

[116] Strawbridge WJ, Shema SJ, Balfour JL, Higby HR, Kaplan GA (1998) Antecedents of frailty over three decades in an older cohort. J Gerontol B Psychol Sci Soc Sci 53B, S9-S16.

[117] Sternberg SA, Wershof Schwartz A, Karunananthan S, Bergman H, Mark Clarfield A (2011) The identification of frailty: A systematic literature review. J Am Geriatr Soc 59, 2129-2138.

[118] Fries J (1980) Aging, natural death and the compression of morbidity. N Engl J Med 303, 130-135.

[119] Mor V (2005) The compression of morbidity hypothesis: A review of research and prospects for the future. $J \mathrm{Am}$ Geriatr Soc 53(9 Suppl), S308-S309.

[120] Canevelli M, Cesari M (2015) Cognitive frailty: What is still missing? J Nutr Heal Aging 19, 273-275.

[121] de Labra C, Guimaraes-Pinheiro C, Maseda A, Lorenzo T, Millán-Calenti JC (2015) Effects of physical exercise interventions in frail older adults: A systematic review of randomized controlled trials. BMC Geriatr 15, 154.

[122] Hopman P, de Bruin SR, Forjaz MJ, Rodriguez-Blazquez C, Tonnara G, Lemmens LC, Onder G, Baan CA, Rijken M (2016) Effectiveness of comprehensive care programs for patients with multiple chronic conditions or frailty: A systematic literature review. Health Policy 120, 818-832.

[123] Wilson MG, Béland F, Julien D, Gauvin L, Guindon GE, Roy D, Campbell K, Comeau DG, Davidson H, Raina P, Sattler D, Vrkljan B (2015) Interventions for preventing, delaying the onset, or decreasing the burden of frailty: An overview of systematic reviews. Syst Rev 4, 128.

[124] Jadczak AD, Makwana N, Luscombe-Marsh ND, Visvanathan R, Schultz TJ (2016) Effectiveness of exercise interventions on physical function in community-dwelling frail older people: An umbrella review protocol. JBI Database System Rev Implement Rep 14, 93-102.

[125] Theou O, Stathokostas L, Roland KP, Jakobi JM, Patterson C, Vandervoort AA, Jones GR (2011) The effectiveness of exercise interventions for the management of frailty: A systematic review. J Aging Res 2011, 569194.

[126] Cadore EL, Rodríguez-Mañas L, Sinclair A, Izquierdo M (2013) Effects of different exercise interventions on risk of falls, gait ability, and balance in physically frail older adults: A systematic review. Rejuvenation Res 16, 105114.

[127] Kelaiditi E, Guyonnet S, Cesari M (2015) Is nutrition important to postpone frailty? Curr Opin Clin Nutr Metab Care 18, 37-42.

[128] Morley JE, Morris JC, Berg-Weger M, Borson S, Carpenter BD, Del Campo N, Dubois B, Fargo K, Fitten
LJ, Flaherty JH, Ganguli M, Grossberg GT, Malmstrom TK, Petersen RD, Rodriguez C, Saykin AJ, Scheltens P, Tangalos EG, Verghese J, Wilcock G, Winblad B, Woo J, Vellas B (2015) Brain health: The importance of recognizing cognitive impairment: An IAGG consensus conference. J Am Med Dir Assoc 16, 731-739.

[129] Ngandu T, Lehtisalo J, Solomon A, Levälahti E, Ahtiluoto S, Antikainen R, Bäckman L, Hänninen T, Jula A, Laatikainen T, Lindström J, Mangialasche F, Paajanen T, Pajala S, Peltonen M, Rauramaa R, Stigsdotter-Neely A, Strandberg T, Tuomilehto J, Soininen H, Kivipelto M (2015) A 2 year multidomain intervention of diet, exercise, cognitive training, and vascular risk monitoring versus control to prevent cognitive decline in at-risk elderly people (FINGER): A randomised controlled trial. Lancet $\mathbf{3 8 5}$, 2255-2263.

[130] Dedeyne L, Deschodt M, Verschueren S, Tournoy J, Gielen E (2017) Effects of multi-domain interventions in (pre)frail elderly on frailty, functional, and cognitive status: A systematic review. Clin Interv Aging 12, 873-896.

[131] Landi F, Abbatecola AM, Provinciali M, Corsonello A, Bustacchini S, Manigrasso L, Cherubini A, Bernabei R, Lattanzio F (2010) Moving against frailty: Does physical activity matter? Biogerontology 11, 537-545.

[132] van de Rest O, van der Zwaluw NL, Tieland M, Adam JJ, Hiddink GJ, van Loon LJ, de Groot LC (2014) Effect of resistance-type exercise training with or without protein supplementation on cognitive functioning in frail and prefrail elderly: Secondary analysis of a randomized, doubleblind, placebo-controlled trial. Mech Ageing Dev 136-137, 85-93.

[133] Langlois F, Vu TT, Chassé K, Dupuis G, Kergoat MJ, Bherer L (2013) Benefits of physical exercise training on cognition and quality of life in frail older adults. J Gerontol B Psychol Sci Soc Sci 68, 400-404.

[134] Fougère B, Delrieu J, Del Campo N, Soriano G, Sourdet S, Vellas B (2017) Cognitive Frailty: Mechanisms, tools to measure, prevention and controversy. Clin Geriatr Med 33, 339-355.

[135] Canevelli M, Cesari M (2017) Cognitive frailty: Far from clinical and research adoption. $J$ Am Med Dir Assoc 18, 816-818.

[136] St John PD, Tyas SL, Griffith LE, Menec V (2017) The cumulative effect of frailty and cognition on mortality results of a prospective cohort study. Int Psychogeriatr 29, 535-543.

[137] Ma L, Zhang L, Zhang Y, Li Y, Tang Z, Chan P (2017) Cognitive frailty in China: Results from China Comprehensive Geriatric Assessment Study. Front Med 4, 174.

[138] Song X, Mitnitski A, Rockwood K (2011) Nontraditional risk factors combine to predict Alzheimer disease and dementia. Neurology 77, 227-234.

[139] Rosado-Artalejo C, Carnicero JA, Losa-Reyna J, Guadalupe-Grau A, Castillo-Gallego C, Gutierrez-Avila G, Alfaro-Acha A, Rodríguez-Artalejo F, RodríguezMañas L, García-García FJ (2017) Cognitive performance across 3 frailty phenotypes: Toledo Study for Healthy Aging. J Am Med Dir Assoc 18, 785-790. 